\title{
Fake news y coronavirus: detección de los principales actores y tendencias a través del análisis de las conversaciones en Twitter
}

\author{
Fake news and coronavirus: Detecting key players and \\ trends through analysis of Twitter conversations
}

\author{
Jesús-Ángel Pérez-Dasilva; Koldobika Meso-Ayerdi; Terese Mendiguren-Galdospín
}

Cómo citar este artículo:

Pérez-Dasilva, Jesús-Ángel; Meso-Ayerdi, Koldobika; Mendiguren-Galdospín, Terese (2020). “Fake news y coronavirus: detección de los principales actores y tendencias a través del análisis de las conversaciones en Twitter". El profesional de la información, v. 29, n. 3, e290308.

https://doi.org/10.3145/epi.2020.may.08

Artículo recibido el 16-04-2020 Aceptación definitiva: 07-05-2020

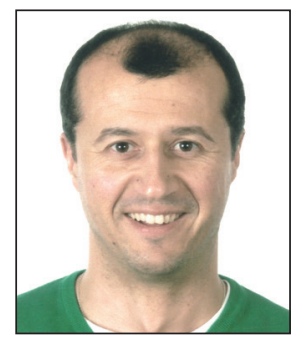

Jesús-Ángel Pérez-Dasilva $\square$ http://orcid.org/0000-0002-3383-4859

Universidad del País Vasco (UPV/EHU) Facultad de Ciencias Sociales y de la Comunicación

Barrio Sarriena, $\mathrm{s} / \mathrm{n}$. 48940 Leioa (Bizkaia), España jesusangel.perez@ehu.eus

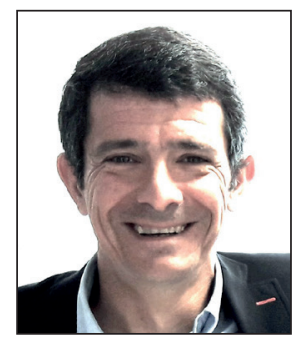

Koldobika Meso-Ayerdi http://orcid.org/0000-0002-0400-133X

Universidad del País Vasco (UPV/EHU) Facultad de Ciencias Sociales y de la Comunicación Barrio Sarriena, s/n. 48940 Leioa (Bizkaia), España koldo.meso@ehu.eus

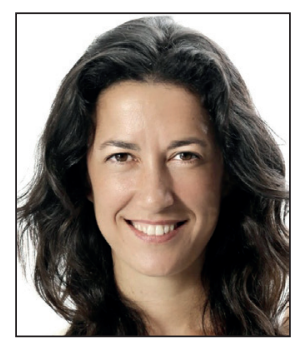
Terese Mendiguren-Galdospín http://orcid.org/0000-0003-3092-6608
Universidad del País Vasco (UPV/EHU)
Facultad de Ciencias Sociales y de la
Comunicación
Barrio Sarriena, s/n.
48940 Leioa (Bizkaia), España
terese.mendiguren@ehu.eus

\section{Resumen}

La crisis sanitaria global surgida por la expansión del Covid-19 ha llevado a la OMS a acuñar el término infodemia para definir una situación de miedo e inseguridad en la que la difusión de información falsa se ha generalizado. Estos bulos se aprovechan de este tipo de emociones para propagarse más rápido que el propio coronavirus, generando a su paso temor y desconfianza en la población. La difusión de estas mentiras, parte de las cuales circula por las redes sociales, resulta peligrosa porque afecta a la salud y puede hacer que se agrave el contagio y provocar la muerte de personas. Esta investigación tiene como objetivo analizar y visualizar la red tejida alrededor de las noticias falsas que circulan en Twitter sobre la pandemia del coronavirus mediante la técnica del análisis de redes sociales. Se ha empleado el software NodeXL Pro. Se han utilizado varias medidas de centralidad para generar la red de conexiones entre los usuarios, representar sus patrones de interacción e identificar los actores clave dentro de la estructura. Además, también se ha creado una red semántica para descubrir las diferencias en la forma en que los grupos de personas hablan sobre el tema. Los resultados

\section{Financiación}

Esta investigación forma parte del proyecto financiado por el Ministerio de Ciencia, Innovación y Universidades de España “Noticias, Redes y Usuarios en el Sistema de Medios Híbridos: Creación y Difusión Compartida de Noticias en Medios Online", RTI2018-095775-B-C41. Igualmente, se llevó a cabo dentro del Grupo de Investigación Consolidado 'Gureiker' (A) (IT1112-16), financiado por el Gobierno Vasco. 
muestran que la situación en EUA domina la conversación, pese a que en ese momento apenas registraba casos y Europa se había convertido en el epicentro global del Covid-19. A pesar de las acusaciones de inacción de periodistas y críticos del gobierno de Trump, se observan varias semanas en las que la desinformación distrae de tomar medidas más eficaces y prevenir verdaderamente el contagio. Además, entre los actores con posiciones más destacadas en la red se constata la escasa presencia de científicos e instituciones que ayuden a desmentir los bulos y expliquen las medidas de higiene.

\title{
Palabras clave
}

Coronavirus; Covid-19; Pandemias; Salud; Crisis sanitarias; Información de salud; Noticias falsas; Difusión de información; Desinformación; Conversación; Comunicación política; Medios sociales; Análisis de redes sociales; Twitter; NodeXL; Donald Trump.

\begin{abstract}
The global health crisis arising from the expansion of Covid-19 has led the WHO to coin the term infodemics to define a situation of fear and insecurity in which the dissemination of false information has become widespread. These hoaxes take advantage of this type of emotion to spread faster than the coronavirus itself, generating fear and distrust in the population. The spread of these lies, part of which circulates on social networks, is dangerous because it affects health and can make the contagion worse and cause people to die. This research aims to analyse and visualise the network created around the false news circulating on Twitter about the coronavirus pandemic using the technique of social network analysis. NodeXL Pro software has been used. Several measures of network centrality have been used to generate the network of connections between users, to represent their interaction patterns and to identify the key actors within the network. In addition, a semantic network has also been created to discover the differences in the way groups of people talk about the topic. The results show that the situation in the USA dominates the conversation, despite the fact that at that time there were hardly any cases, and Europe had become the global epicentre of the Covid-19. Despite reports of inaction by journalists and critics of the Trump government, there are several weeks in which disinformation distracts from taking more effective action and actually preventing contagion. Moreover, among the actors with the most prominent positions in the network, there is little presence of scientists and institutions that help to disprove the hoaxes and explain the hygiene measures.
\end{abstract}

\section{Keywords}

Coronavirus; Covid-19; Pandemics; Health; Health crisis; Health information; Fake news; Information dissemination; Disinformation; Conversation; Political communication; Social media; Social network analysis; Twitter; NodeXL; Donald Trump.

\section{Introducción}

El 31 de diciembre de 2019, China informó de casos de neumonía en personas asociados con el mercado mayorista de mariscos de Huanan en Wuhan, provincia de Hubei. El 7 de enero de 2020, las autoridades sanitarias chinas confirmaron que este grupo estaba relacionado con un nuevo coronavirus, 2019-nCoV o Covid-19. Aunque en un principio se informó de que los casos estaban asociados con la exposición al mercado de mariscos de Wuhan, pronto los datos epidemiológicos indicaron que se estaba produciendo la transmisión de 2019-nCoV de persona a persona. Al 30 de enero de 2020 se habían notificado un total de 9.976 casos en al menos 21 países. El 12 de marzo, la Organización Mundial de la Salud (OMS) pasó a calificar de pandemia el brote tras los elevados casos de contagio del nuevo coronavirus. Para entonces, ya se contabilizaban más de 118.000 casos en 114 países y 4.291 muertes.

Durante las primeras cuatro semanas de enero de 2020, hubo más de 15 millones de publicaciones en Twitter sobre el tema del coronavirus, y sólo el día que pasó a ser calificado como pandemia se publicaron casi diez millones de contenidos en la red de microblogging, según el blog de análisis de medios sociales Tweet Binder.

Hasta mediados de abril, cuando ya más de 417 millones de tweets abordan el tema del coronavirus, la teoría de conspiración más preocupante que circula en línea se relaciona con la afirmación ficticia de que el virus fue diseñado por los chinos, con objetivos políticos o económicos (Gonçalves-Sá, 2020).

Sin embargo, las diferentes especulaciones y teorías sobre los orígenes del Covid-19 han continuado creciendo a la misma velocidad que el virus se expande por todo el mundo. Paralelamente, también se ha denunciado el cada vez mayor número de desinformaciones sobre la prevención, el tratamiento y otros aspectos de la enfermedad.

La pandemia mundial, que está matando a miles de personas y ha cerrado las fronteras, está inundada de desinformación. La Organización Mundial de la Salud declaró en febrero una "infodemia" (infodemic), una sobreabundancia de información -alguna exacta y otra no- que hacía difícil que las personas encontrasen fuentes fiables y orientación confiable cuando la necesitaban. El Director General de la OMS, Tedros Adhanom Ghebreyesus, dijo en la Conferencia de Seguridad de Munich en febrero:

“Las noticias falsas se propagan más rápido y más fácilmente que este virus, y es igual de peligroso". 


\section{Marco teórico}

La facilidad de acceso a los medios sociales los ha convertido en un importante lugar de debate sobre la salud y un recurso tanto para los profesionales sanitarios como para los pacientes y para aquellos que buscan o intercambian información sobre este tema. Una encuesta de 2011 ya indicaba que el 62\% de los usuarios adultos de Internet en los Estados Unidos utilizaban las redes sociales para temas relacionados con la salud (Fox, 2011).

Sin embargo, a pesar de las importantes posibilidades para la difusión de información objetiva, los medios sociales se utilizan frecuentemente para difundir información errónea, expandir falsas informaciones o datos sin verificar sobre contenidos de salud (Kata, 2012). Con escasas limitaciones legales impuestas a los sitios web, los medios sociales proporcionan un foro dinámico para propagar posible información médica de dudosa calidad (Frish; Greenbaum, 2017). De hecho, son muchos los autores que cuestionan la calidad de la información disponible, así como las motivaciones de los contenidos (Ghenai; Mejova, 2018; Moorhead et al., 2013).

Un buen ejemplo de ello son los debates en Twitter en torno a las virtudes o las ineficacias de las vacunas (Broniatowski et al., 2018) o el Alzheimer (Cheng et al., 2018). Del mismo modo, las plataformas para intercambiar o subir imágenes como Flickr e Instagram se han convertido en espacios de discusión sobre los trastornos de la conducta alimentaria (Yom-Tov et al., 2012), un tema recurrente en los medios sociales (Wang et al., 2017). La incertidumbre que rodea la progresión de brotes de enfermedades infecciosas, como la epidemia de Zika de 2016, ha dado lugar a rumores y especulaciones sobre sus causas, medidas preventivas y consecuencias en las redes sociales (Dredze et al., 2016; Ghenai; Mejova, 2017). O con el Ébola, analizándose los tipos de comunicación de tres importantes organizaciones de salud que se utilizaron durante el brote, el contenido y el contexto de esas comunicaciones y las respuestas que suscitaron en el público (Guidry et al., 2017).

Gran parte de esta información errónea sobre la salud puede ser propulsada por bots (Chu et al., 2012) y trolls (Jamison et al., 2019). De hecho, algunas investigaciones han demostrado que tanto los trolls como los bots constituyen poderosas tácticas para manipular la opinión pública y sembrar la confusión entre los usuarios (Sharevski et al., 2020).

La desinformación en los medios sociales es un tema urgente, y más aún en el campo de la salud (Ghenai; Mejova, 2018). Esta investigación es una de las primeras en examinar las características de los usuarios que propagan contenidos sobre el coronavirus en Twitter como un caso de estudio de seguimiento de la desinformación sobre la salud. La identificación de los posibles actores de esa información errónea permitiría a las autoridades de la salud pública controlar el discurso de los medios de comunicación social, distinguir las deficiencias de las actuales estrategias de comunicación en torno a la salud, y detectar la información errónea antes de que pueda causar un daño irreparable.

\section{Estado de la cuestión}

El presente trabajo combina dos tendencias florecientes en la investigación sobre los medios sociales: el aumento de las informaciones falsas y las actitudes y actuaciones relacionadas con la salud. A continuación, describimos los últimos avances en ambos temas, así como los recientes intentos de indagar en la desinformación sobre la salud en particular.

\subsection{Información errónea. Orígenes}

En 2017, el Oxford English Dictionary designó el término fake news como Palabra del Año, refiriéndose a él como información falsa diseminada bajo la apariencia de un reportaje cuyo contenido es frecuentemente sensacionalista. Sin embargo, el uso deliberado de información que no se corresponde con la realidad no es un hecho relativamente reciente. Las noticias falsas comenzaron a surgir en el siglo XIX en un momento de rápido crecimiento para los periódicos ayudado por las tecnologías emergentes en aquel entonces (Berkowitz; Schwartz, 2016). Pero ya antes, durante la rebelión Jacobita en Gran Bretaña, a mediados del siglo XVIII, impresores sediciosos difundieron que el rey Jorge II estaba gravemente enfermo en un intento de desestabilizar al gobierno del monarca. Dichas noticias fueron recogidas por medios serios haciéndose más difícil discernir entre realidad y ficción.

En mayo de 1803, mientras Gran Bretaña se preparaba para poner fin al Tratado de Amiens y declarar la guerra a Francia, el por entonces alcalde de Londres, Sir Charles Price, recibió una carta presuntamente escrita por Lord Hawkesbury y sellada con su sello personal. La misiva afirmaba que la disputa con Francia se había resuelto amistosamente. El alcalde llevó la carta a la Bolsa de Valores para compartir la alegre noticia. Cuando se demostró que tal información era falsa, muchas acciones habían cambiado de manos y fueron muchos los que se enriquecieron con esta acción.

Ambos hechos sirven para ejemplificar como, en el contexto de las noticias, los rumores y la desinformación se han asociado con la esfera política, con campañas organizadas ligadas a gobiernos. Por ejemplo, se difundió que el papa apoyaba a Donald Trump o que Hillary Clinton vendía armas a Isis. Sin embargo, desde finales del siglo XX se conoce la existencia de otro tipo de campañas de desinformación a gran escala relacionadas con el cambio climático, la ciencia, las vacunas, los alimentos, la nutrición, el origen de la vida, la salud, los medicamentos genéricos, la curación u origen de enfermedades o la inmigración, entre otras muchas cuestiones.

Pero sin duda, el momento más álgido del fenómeno de las fake news se vincula con dos importantes decisiones políticas que se produjeron en 2016: el proceso del Brexit en el Reino Unido y la elección de Donald Trump como presidente 
de los Estados Unidos. De hecho, algunas investigaciones demostraron que durante la campaña electoral se generó un importante número de noticias falsas favorables al actual presidente (Allcott; Gentzkow, 2017).

La verificación de la información es una de las características básicas de la producción periodística, si bien la calidad de este proceso está muchas veces en entredicho (Vázquez-Herrero et al., 2019). Esto se debe tanto a la aceleración constante del trabajo informativo que ha traído consigo Internet (Currie-Sivek; Bloyd-Peshkin, 2018), como a la facilidad para la difusión de informaciones falsas en las redes sociales en un momento en el que el consumo informativo se ha incrementado notablemente en esas plataformas (Zubiaga et al., 2016).

Sea como fuere, la detección de noticias falsas en los medios sociales, con el objetivo de evitar o mitigar los efectos de su proliferación (Gueham, 2017) se ha convertido recientemente en una investigación emergente que está atrayendo una enorme atención. La localización de este tipo de contenidos en los medios sociales presenta características y desafíos únicos que hacen que algunas investigaciones propongan para combatir esta situación soluciones de minería de datos (Shu et al., 2017), de carácter colaborativo (crowdsourcing), abriendo el proceso de evaluación de los contenidos a los usuarios de las redes permitiéndoles calificarlos según su criterio y decidir si les otorga o no credibilidad (Pauner-Chulvi, 2018); o soluciones basadas en procedimientos automáticos y el desarrollo de algoritmos (Shao et al., 2018; Vosoughi et al., 2017), ya que hay estudios que evidencian que los materiales informativos elaborados mediante inteligencia artificial resultan más creíbles que los elaborados por humanos (Túñez-López et al., 2018).

\subsection{Desinformación, salud y Twitter}

Pero más allá de la política, las redes sociales también proporcionan grandes recursos para debatir en torno a la salud. Uno de los temas que suscita más discusión en los medios sociales y que, por tanto, puede llegar potencialmente a una población más grande, es el que hace referencia a las vacunas (Xu, 2019; Xu et al., 2019), fundamentalmente porque el suministro de información y experiencias es rápido y eficaz (Javanainen, 2020).

Sin embargo, la amalgama de temas es muy variada, tanto como el empleo de diferentes medios sociales. YouTube ha servido como plataforma en la que polemizar sobre el cáncer de próstata (Hou et al., 2019) o la anorexia (Syed-Abdul et al., 2013). Los hilos de los foros, por ejemplo, fueron empleados para debatir sobre los efectos de las drogas (Yang; Yang, 2013) mientras que Instagram y Facebook fueron las plataformas en las que se discutía sobre las actitudes relacionadas con las enfermedades vinculadas con estilos de vida como la diabetes y la obesidad (Chung et al., 2017) y los desórdenes alimenticios (Mejova et al., 2015; Araujo et al., 2017).

La difusión de información errónea sobre la salud también se ha dado en las aplicaciones de los medios sociales como WeChat (Gu; Hong, 2019).

Sin embargo, Twitter es la plataforma que desempeña un papel fundamental en la difusión de información sobre la salud (Bakal; Kavuluru, 2017), si bien las pruebas sugieren que una alta proporción de los mensajes de la red de microblogging no es necesariamente exacta, y muchos estudios demuestran que los tweets no necesitan ser estrictos, o al menos estar basados en pruebas, para recibir tracción. Esta es una combinación peligrosa en la esfera de la información sobre la salud (Albalawi et al., 2019).

Son muchos los puntos fuertes que tiene esta red social: amplia audiencia, comunicación instantánea o información en tiempo real, entre otros aspectos. Sin embargo, también presenta limitaciones que dificultan su uso en un contexto de emergencia: dificultad por verificar la información verificada, rumores, imprecisión en los datos o existencia de información irrelevante (Laylavi et al., 2017; Stieglitz et al., 2018).

La naturaleza dinámica de los medios sociales ha posibilitado la difusión de información poco fiable o errónea durante una epidemia en curso, como por ejemplo durante el brote de Zika en 2016 (Wood, 2018), en que se abrió un agrio debate sobre las teorías de conspiración sobre el origen del virus.

La desinformación en una pandemia no es nueva. Por ejemplo, la operación Infektion fue una campaña de guerra de información de la KGB para difundir el rumor, en el decenio de 1980, de que el VIH/SIDA era un arma biológica estadounidense que no funcionaba (Cosentino, 2020).

El debate en torno al virus Covid-19 tampoco se escapa a los debates conspirativos. Primero fue que el coronavirus se había creado en un laboratorio secreto del gobierno en China. Después surgieron medicinas falsas sobre productos que ofrecían inmunización contra el virus. Y posteriormente, hubo afirmaciones falsas sobre gobiernos y celebridades.

El grado de desinformación aumentó a medida que el Covid-19 se extendía a nivel mundial, a pesar de los esfuerzos de medios sociales como Facebook, Google y Twitter para limitar su difusión. Incluso los propios usuarios parecen estar cada vez más concienciados en combatir la información falsa y han comenzado a marcar los contenidos en cuanto detectan que no transmiten información fiable. 
La desinformación en el caso del Covid-19 parece plantear un riesgo tanto para la salud como para la seguridad mundial, ya que no basta con asegurarse de que la gente esté informada, sino de que esté bien informada para actuar adecuadamente.

En esta crisis, incluso las propias autoridades en las que la gente confía están demostrando una ausencia clara de información. Jefes de estado, políticos, funcionarios y medios de comunicación estatales están actuando de manera irresponsable, convirtiéndose en propagadores de esa desinformación. Un portavoz del gobierno chino expandió el rumor de que el virus fue traído a China por Estados Unidos, lo que poco después fue reportado en los medios de comunicación estatales chinos.

Los medios rusos también sugirieron que el Covid-19 fue creado en un laboratorio de Estados Unidos en Georgia. Y el presidente de Venezuela, Nicolás Maduro, dijo que el virus era una posible arma biológica dirigida a China, además de recomendar recetas naturales para curar el virus en un tweet que fue eliminado por Twitter.

El presidente Donald Trump también tergiversó constantemente la escala y la respuesta al coronavirus en Estados Unidos. Cuestionó la tasa de mortalidad en una entrevista con Sean Hannity en la cadena estadounidense Fox News e incluso afirmó que el coronavirus no era peor que una gripe. Los políticos americanos también impulsaron la conspiración de que el virus se originó en un laboratorio de China.

\section{Objetivos}

El objetivo genérico de esta investigación es analizar y visualizar la red tejida alrededor de las noticias falsas que circulan en Twitter sobre la pandemia del coronavirus mediante la técnica del análisis de redes sociales (ARS). Contiene los siguientes objetivos específicos:

01. Identificar a los actores principales. Averiguar qué usuarios son los que tienen una mayor capacidad para controlar la difusión de los mensajes y la relevancia o autoridad que los usuarios llegan a tener en la red analizada.

O2. Estudiar la red semántica surgida en torno a los bulos sobre el coronavirus y establecer el contenido predominante en dichos mensajes.

\section{Hipótesis}

H1. Los científicos o expertos que orientan sobre las medidas de higiene a adoptar y ayudan a desmentir los bulos suponen una minoría entre los actores que presentan mayor ventaja estructural en la red (relacionado con 01).

$\mathrm{H} 2$. Predominan las conversaciones (relacionado con $\mathrm{O} 2$ ) que distraen de tomar medidas más eficaces y prevenir verdaderamente el contagio sobre los que quieren desmentir los bulos sobre el coronavirus con un objetivo de educar e informar.

H3. Los hilos de conversación y/o actores con posiciones más relevantes en la red están relacionados con países europeos como Italia o España ya que durante el periodo de estudio Europa sustituye a China como epicentro de la pandemia del coronavirus (relacionado con $\mathrm{O} 1$ y $\mathrm{O} 2$ ).

\section{Metodología}

En este artículo se ha estudiado, mediante la técnica del análisis de redes sociales (Borgatti et al., 2009; Freeman, 2004; Otte; Rousseau, 2002; Wasserman; Faust, 1994), la estructura de las relaciones en la red tejida en torno a los bulos que hacen referencia al coronavirus en la plataforma Twitter. La elección de esta red social para la investigación se ha debido a que es una plataforma abierta (Williams et al., 2013) que, al contrario que aplicaciones como Facebook o YouTube, permite observar sin restricciones los flujos de información entre sus usuarios (Wu et al., 2011). Twitter ofrece un entorno interesante para la investigación porque genera una cantidad enorme de interacciones interpersonales que proporcionan un importante conjunto de datos que pueden ser empleados por los investigadores académicos para estudiar los procesos de difusión de información en las redes sociales (Brubaker; Wilson, 2018; Benson, 2016; Evans, 2016; Boyd, 2014; Tolson, 2010). En este sentido, a diferencia de otras redes como Facebook, Twitter está especialmente dirigida a difundir informaciones, lo que la convierte en un valioso laboratorio natural para estudiar los mecanismos de difusión de información (Bakshy et al., 2011). Además, es un servicio de gran viralidad donde los contenidos se extienden a millones de usuarios de manera espontánea y descontrolada lo que ha convertido a esta plataforma en una de las influencias más importantes en la formación de la opinión de los usuarios sobre diferentes temas (Leonhardt, 2015; Mohr, 2014). La elección de Twitter, como se ha mencionado en apartados anteriores, también ha venido determinada por diferentes trabajos que destacan su capacidad para capturar tendencias epidémicas, recopilar información y difundir conocimiento durante crisis de salud pública (Odlum; Yoon, 2015; Scanfeld et al., 2010).

La identificación de los actores principales en la red surgida alrededor del objeto de estudio y la captura de los flujos de información y patrones de interacción se ha realizado con el software NodeXL, uno de los principales programas de análisis de redes sociales (Hansen; Shneiderman; Smith, 2010; Smith et al., 2010) que ha sido
A partir de finales de febrero las referencias a las medidas de prevención e higiene para contener la propagación del virus escalan posiciones entre los términos con conexiones más fuertes 
utilizado en los últimos 10 años para estudiar diferentes temas como las conexiones entre políticos y periodistas (Verweij, 2012), el uso de hashtags y trending topics durante desastres como la bomba en el maratón de Boston (Wukich; Steinberg, 2013), la difusión de hashtags (Dos-

sis; Amanatidis; Mylona, 2015), el caso del movimiento Occupy Wall Street (Park; Lim; Park, 2015) o los procesos de difusión de noticias (Ahmed; Lugovic, 2019), entre otros. Asimismo NodeXL también se ha empleado para estudiar la difusión de información de salud a través de las redes sociales como las investigaciones sobre las comunidades surgidas en torno a enfermedades como el cáncer (Bae; Kwon; Cho, 2019; Himelboim; Han, 2014), la propagación de enfermedades infecciosas como la peste porcina africana (Lichoti et al., 2016), como un método de vigilancia en tiempo real para monitorear la propagación de información, o capturar la detección temprana de pandemias y examinar el conocimiento y las actitudes del público durante el brote del Ébola (Herchel-Thaddeus, 2016).

El proceso de extracción de datos se ha realizado el 28 de febrero y el 12 de marzo de 2020 y se han recopilado los tweets que contienen los términos coronavirus, Covid-19 y fake news. En primer lugar, se ha escogido el 28 de febrero porque ese día la OMS elevó a "muy alto" el riesgo de propagación del coronavirus. En ese momento la situación parecía estar controlada en China, pero se confirmó que el virus llevaba varios días circulando por España (aumentó el número de casos positivos hasta 33) e Italia se convirtió en el foco de la pandemia en Europa y en el origen de los casos de México y Brasil. En segundo lugar, la elección del 12 de marzo se ha debido a que el descontrol del brote en Europa llevó a la OMS a declarar ese día el brote de coronavirus como pandemia global. Se suspendieron los vuelos Europa-EUA; Italia clausuró todos los negocios del país, excepto farmacias y tiendas de alimentación; y España cerró los colegios y suspendió actividades como los encuentros deportivos. La Bolsa también se desplomó.

La base de datos, que se ha obtenido de la API de Twitter a través del software NodeXL, ha extraído 21.371 nodos o actores y 23.869 interacciones entre el 23 de enero y el 28 de febrero. Entre el 28 y el 12 de marzo ha capturado 34.505 actores y 37.362 relaciones.

Para medir y comprender la importancia de los nodos en la red tejida en torno a las noticias falsas sobre el coronavirus se han empleado las dos métricas de centralidad más comunes tradicionalmente utilizadas en ARS (Scott; Carrington, 2014): centralidad de grado e intermediación. El nivel de centralidad de los actores se ha representado mediante el tamaño del nodo.

- Centralidad de grado: Se ha considerado importante centrar el análisis en la centralidad del grado de entrada frente a la del grado de salida (Aguilar-Gallegos et al., 2016) porque el grado de salida, que es el número de vínculos que envía un actor hacia otros actores, no sirve como medida de su influencia en redes como Twitter (Fernández, 2019). Se ha entendido por grado de entrada el número de vínculos que ha recibido un nodo o actor provenientes de otros actores. Un valor alto ha significado que estos actores han sido influyentes porque muchos usuarios les han referenciado y viralizado sus publicaciones. Es decir, muchos perfiles han procurado tener vínculos directos con ellos.

- Grado de intermediación: Ha servido para medir el número de veces en que un nodo o usuario ha sido el recorrido más corto entre dos usuarios en una red y ha indicado qué usuarios son los que han tenido una mayor capacidad para controlar la difusión de un mensaje (Hansen et al., 2010). Un valor alto ha significado que ese usuario ha sido un punto de conexión por el que ha fluido información relevante y ha podido ayudar a que se difunda o bloquearla para otras partes de la red (Lipschultz, 2017). Un valor bajo ha indicado que esos usuarios solo han aportado contenidos redundantes.

“Estos usuarios son de vital importancia para la estructura de la red y son importantes por tres razones: 1) están en mejor posición que otros en cuanto al acceso a la información; 2) son un puente hacia diferentes personas de otras redes, que tienen el potencial de llevar el mensaje más lejos y así aumentar el alcance; 3) están conectados a diferentes personas, y tienen mayores posibilidades de tener acceso a diferente información" (Gibbs; McKendrick, 2015, 220).

Asimismo, los usuarios se han agrupado por conglomerados jerárquicos (análisis de clusters) (Kaleel; Abhari, 2015; Paolillo, 2008) utilizando el algoritmo de Clauset, Newman y Moore (Clauset; Newman; Moore, 2004). Para visualizar la red se ha utilizado el algoritmo de diseño multiescala de Harel y Koren, que ha facilitado la identificación de los actores y sus vínculos (Harel; Koren, 2000).

En segundo lugar se ha efectuado un análisis semántico de los temas presentes en los tweets. Se ha seguido una estrategia de minería de datos basada en la coincidencia de palabras y se han identificado las más importantes siguiendo una frecuencia de documento normalizada y estudiando su presencia en cada mensaje desde una perspectiva relacional (Xiong et al., 2019). Previo al análisis se ha aplicado un protocolo de limpieza para eliminar palabras como conjunciones o preposiciones que no son relevantes y así se han estudiado los sustantivos, verbos, adverbios y adjetivos. La visualización de los resultados en las imágenes se ha limitado a los términos con conexiones más fuertes (Seo et al., 2019). Los datos se han interpretado como gráficos no dirigidos y se ha recurrido al color y tamaño de los nodos para mostrar las palabras que están más conectadas y a la intensidad de la línea que las conecta para representar la fortaleza del vínculo. 


\section{Resultados}

El primer aspecto a tener en cuenta hace referencia a los indicadores de estructura o medidas de cohesión como la densidad o la reciprocidad, que analizan las propiedades de la red completa. En este caso, la relación de pares de vértices recíprocos (reciprocated vertex pair ratio) el 28 de febrero es de 0,000359066 y de 0,000861506 el día 12, unos valores cercanos a cero, lo que significa que solo 3 de cada 1000 y 8 de cada 1000 usuarios tienen una comunicación mutua sobre los bulos del coronavirus. Por otra parte, la media de la distancia geodésica casi se duplica. Aumenta de 3,525706 el día 28 a 6,076026 el día 12, lo que indica que un actor pasa de estar situado a 3,5 pasos de media de cualquier otro a 6 pasos. La cohesión también se puede observar a través de la densidad. En este caso, el día 28 arroja un valor de 4,88025 y disminuye a 2,82984 el día 12. Esto indica que el 28 de febrero la estructura analizada es más densa y que la difusión de bulos sobre el coronavirus entre los nodos se da más rápido que el día 12. Dos semanas después, aumenta la distancia entre los nodos y se reduce algo la velocidad de transmisión de información en la red.

\subsection{Nodos con posiciones más favorables en la red}

Como se aprecia en las figuras 1 y 2, existen diferentes comunidades que definen las dinámicas en la red. Entre el 23 de enero y el 28 de febrero destaca claramente un clúster de gran tamaño (azul oscuro) en torno a @education4libs, seguido por dos grupos grandes (en color azul claro y verde oscuro), 7 agrupaciones de tamaño moderado y un área ocupada por 842 subgrupos débilmente conectados. El 12 de marzo el grafo es diferente y se observan 6 grupos grandes, 20 clúster de tamaño moderado y 1701 subgrupos con una conexión muy débil.

A la hora de estudiar los patrones de interacción y comunicación en la red de microblogging, resulta interesante examinar el grado de entrada de los nodos. Los actores más influyentes (tabla 1) entre el 23 de enero y el 28 de febrero, que ven como sus contenidos sobre el coronavirus son los más referenciados y viralizados por terceros, son 6 estadounidenses y 4 chinos. El valor más alto pertenece a Dylan Wheeler (@education4libs), un autor y comentarista de derechas, que ha sido acusado de tweetear falsedades en varias ocasiones (Skeptical7th, 2019):

"El mercado de valores cayó 1200 puntos hoy, la peor caída de su historia. Esto es lo que sucede cuando los medios de comunicación falsos asustan al público para que crean que el Coronavirus es peor que la gripe española. Harán cualquier cosa para dañar la imagen de Trump antes de la temporada electoral” (Wheeler, 2020).

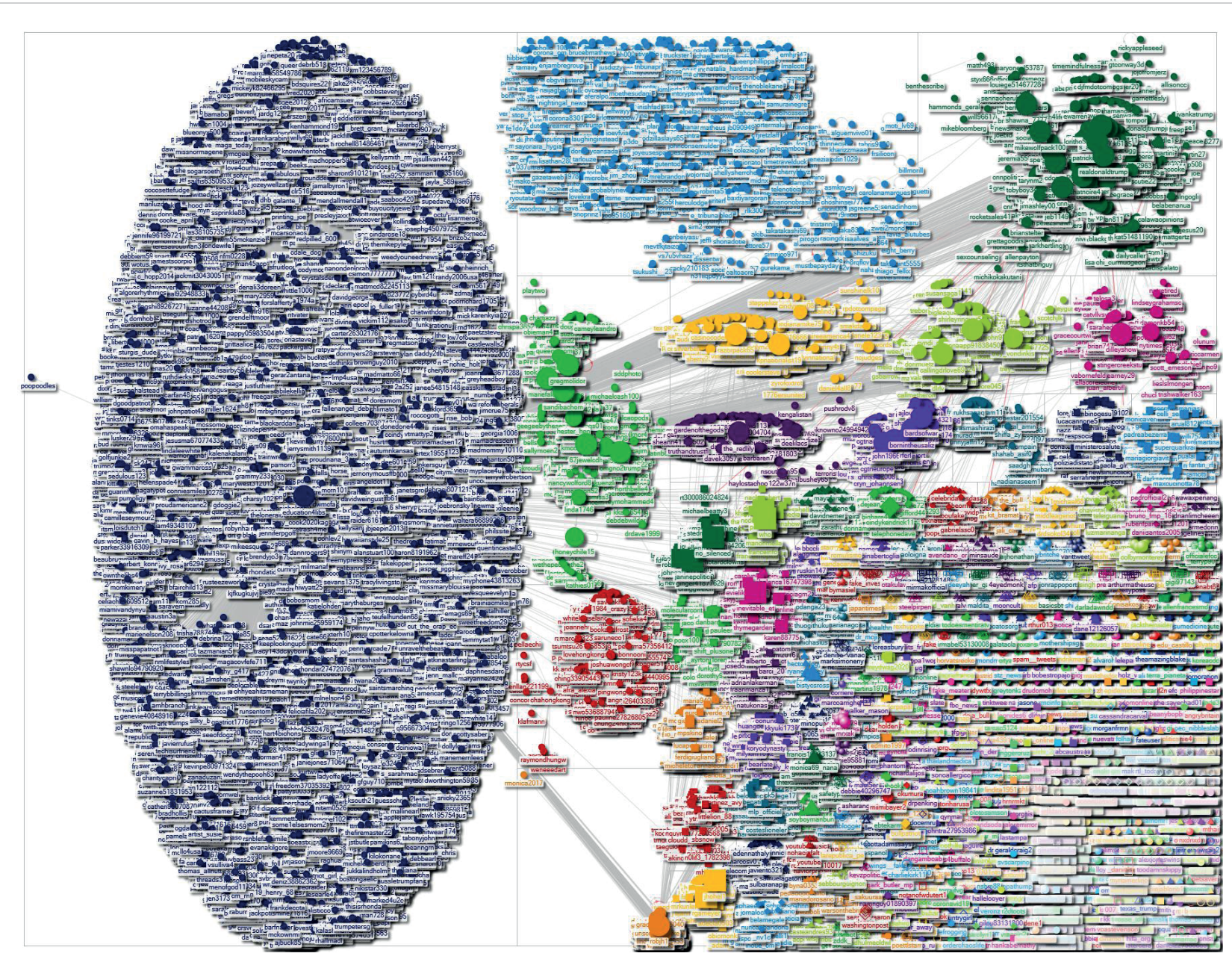

Figura 1. Representación de la red surgida en torno a las noticias falsas sobre el coronavirus entre el 23 de enero y el 28 de febrero de 2020 


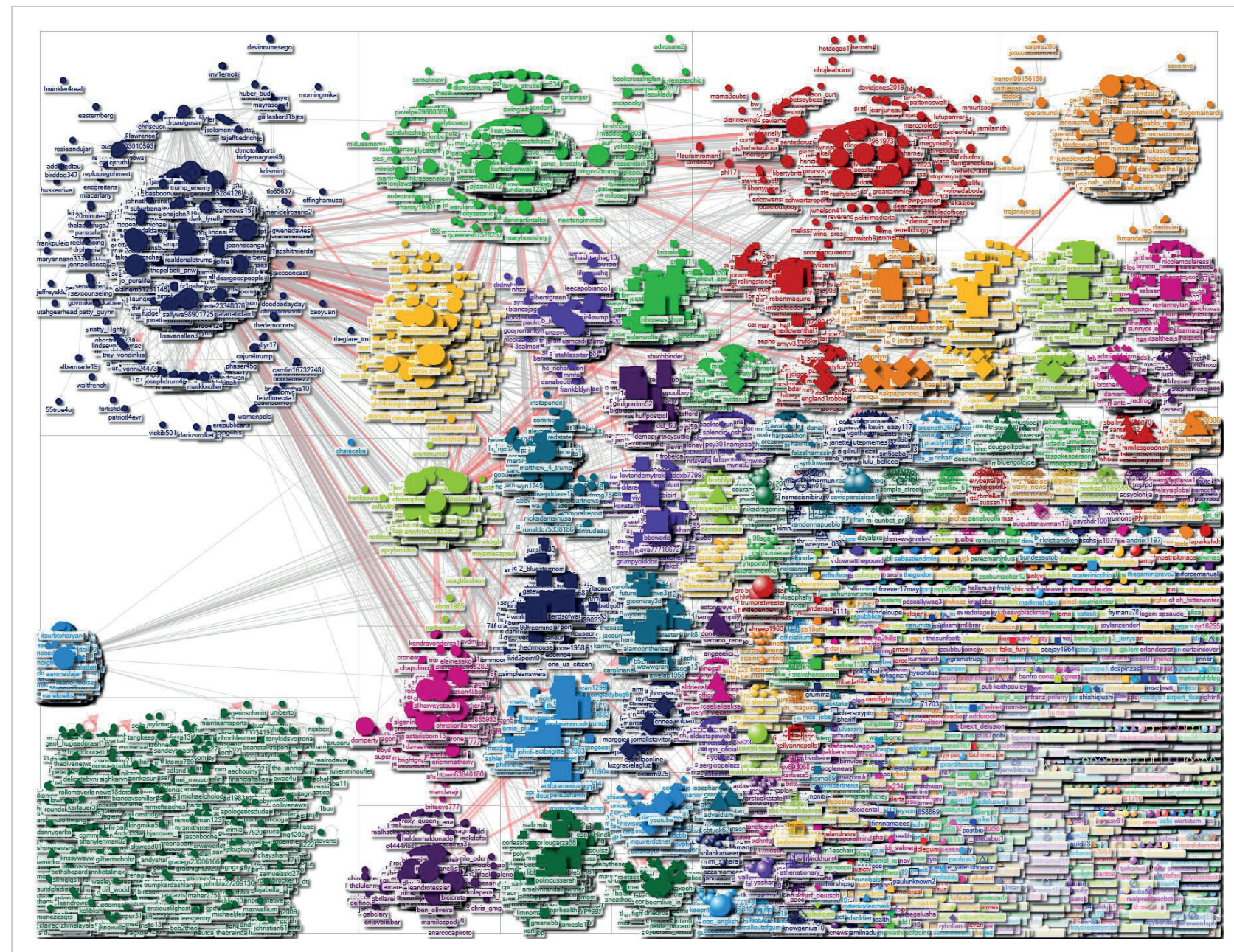

Figura 2. Representación de la red surgida en torno a las noticias falsas sobre el coronavirus entre el 28 de febrero y el 12 de marzo de 2020

En segundo lugar, destaca el presidente Donald Trump porque gran cantidad de usuarios se dirigen a él en sus publicaciones en un intento de generar un vínculo directo. Junto a ellos hay tres usuarios más de ideología conservadora y simpatizantes de su política (@razorpack65, @robjh1 y @the_redlily) con mensajes como el de @robjh1:

"Rush Limbaugh y el Fiscal General Bill Barr llaman a los medios de comunicación de izquierda. Los medios de comunicación de izquierda se han convertido en agentes de división y anarquía. En lugar de informar, buscan atacar y destruir con noticias falsas \#\#FakeNewsMedia \#coronavirus https://t.co/2ygntDSLWR" (Harper, 2020).

No obstante, no todo son apoyos. En tercera posición (2,5\% de las interacciones) se encuentra Carl Hasting (@67jewelcdh), un abogado crítico con Trump:

“Hoy pasé por delante de alguien de una oficina adyacente y le dije: “¿Estás siguiendo esta situación del Coronavirus? Asusta." Ella respondió, “¡Falsas noticias!” Y ahí tienes el peligro de que Trump y Fox ignoren la crisis mundial y culpen a los Demócratas..." (Hasting, 2020).

Por otra parte, entre los 10 primeros hay un grupo formado por cuatro actores chinos que acumulan el 8,7\% de las menciones. Dos guardan relación con Demosisto, un grupo de activistas juveniles de Hong Kong que promueven la democracia y los valores progresistas. Los otros dos están vinculados con Human Rights, una organización dedicada a proteger los derechos humanos de las personas en China. Todos ellos muestran una postura crítica con el gobierno de Pekín:

"El heroico librero de Hong Kong, GuiMinhai fue secuestrado en Tailandia en 2015 por agentes de Pekín. Ahora está encarcelado por 10 años con cargos de espionaje falsos. China anunció la sentencia durante el brote de coronavirus para enterrarlo https://t.co/dJktPpkVQN FOLLOW @demosisto @CHRDnet @hrichina @joshuawongcf"

(Tatchell, 2020).

Por lo tanto, a la luz de estos datos se observa que se traslada a la red la pugna política entre republicanos y demócratas que recurren al coronavirus como arma arrojadiza. Asimismo, cobran relevancia las organizaciones de derechos humanos en China que acusan al gobierno de utilizar la crisis a su favor. En este sentido, resulta revelador obser-
A pesar de que en el momento del estudio Europa se había convertido en el epicentro global del Covid-19, se observa que el cruce de acusaciones entre demócratas y republicanos en Estados Unidos domina la conversación en Twitter 
var que, según el grado de entrada, en las primeras posiciones no encontramos un actor que se centre en las medidas de higiene para prevenir la pandemia o avise contra los bulos que se están difundiendo al respecto.

Tabla 1. Principales actores según el grado de entrada entre el 23 de enero y el 28 de febrero de 2020

\begin{tabular}{|c|c|c|c|c|}
\hline Cuenta & Nombre & Origen & Entrada & Descripción \\
\hline @education4libs & $\begin{array}{l}\text { Educating Liberals } \\
\text { (Dylan Wheeler) }\end{array}$ & EUA & 9.548 & $\begin{array}{l}\text { Digital soldier. Followed by @GenFlynn. Mentioned by Q. Retweeted } \\
\text { by Trump. Shadowbanned by Twitter. Working on becoming an inde- } \\
\text { pendent journalist \#WWG1WGA }\end{array}$ \\
\hline @realdonaldtrump & Donald J. Trump & EUA & 934 & 45th President of the United States of America \\
\hline @67jewelcdh & Carl Hasting & EUA & 618 & $\begin{array}{l}\text { Tax, transactional \& estate planning attorney. Equality, human rights, } \\
\text { animal rights. We can do better. \#TheResistance \#BlueWave2020 } \\
\text { \#BlackLivesMatter }\end{array}$ \\
\hline @joshuawongcf & Joshua Wong & $\begin{array}{l}\text { Hong } \\
\text { Kong }\end{array}$ & 533 & $\begin{array}{l}\text { Activist \#HongKong Secretary General of @demosisto joshua@demo- } \\
\text { sisto.hk \#UnfreeSpeech http://hyperurl.co/unfreespeech Donation: } \\
\text { http://bit.ly/dmstdonation }\end{array}$ \\
\hline @hrichina & $\begin{array}{l}\text { Human Rights in } \\
\text { China }\end{array}$ & China & 533 & $\begin{array}{l}\text { Founded in March 1989, HRIC is dedicated to promoting international } \\
\text { human rights and advancing the institutional protection of these } \\
\text { rights in \#China. }\end{array}$ \\
\hline @chrdnet & $\begin{array}{l}\text { Chinese Human } \\
\text { Rights Defenders }\end{array}$ & China & 533 & $\begin{array}{l}\text { CHRD promotes human rights protection \& empowers grassroots } \\
\text { activism. }\end{array}$ \\
\hline @demosisto & Demosistō & $\begin{array}{l}\text { Hong } \\
\text { Kong }\end{array}$ & 533 & $\begin{array}{l}\text { Movement-oriented youth activist group in Hong Kong that promotes } \\
\text { democracy and progressive values. }\end{array}$ \\
\hline @razorpack65 & $\begin{array}{l}\text { Coral (Text Trump } \\
\text { to } 88022)\end{array}$ & EUA & 447 & Proud American. \\
\hline @robjh1 & $\begin{array}{l}\text { Rob Harper. The } \\
\text { Conservative Black } \\
\text { Cowboy }\end{array}$ & EUA & 381 & $\begin{array}{l}\text { "Vote Red To Save America!" \#BLEXIT } \\
\text { Bandera de Estados Unidos } \\
\text { KAG/ Writer and contributor for http://NewRightNetwork.com and } \\
\text { https://magamedia.org. Arkansas native. }\end{array}$ \\
\hline @the_redlily & Red Lily & EUA & 328 & $\begin{array}{l}\text { God, guns, family and country. • Jesus •PATRIOT •MARRIED •NRA } \\
\cdot \text { BanSHARIA •WWG1WGA •MAGA Ola •FreeGenFlynn •KAG •T2020 } \\
\text {-GreatAwakening •GodBlessOurTroops }\end{array}$ \\
\hline
\end{tabular}

Dos semanas después (tabla 2), sólo repite un perfil en la clasificación de los actores que ven como sus contenidos sobre el coronavirus son los más referenciados y viralizados por terceros. Se trata de Donald Trump, que se sitúa en primer lugar. Algunos de sus mensajes son:

"La revista Vanity Fair, que pronto dejará de existir, y sus reporteros Fake de tercera categoría, que inventan fuentes que no existen, escribieron otro falso aburrido artículo. Los hechos son justo lo contrario. ¡Nuestro equipo está haciendo un gran trabajo con el CoronaVirus!" (Trump, 2020).

Junto a él hay 6 actores estadounidenses más entre los más referenciados. Dos (@USMCSDI y @HarveyStaub1) apoyan a Trump con publicaciones de éxito como:

"Querida América: La única diferencia entre ESTA pandemia de Coronavirus y los otros cientos que hemos tratado es que FAKE NEWS ha decidido POLITIZARLA porque la escoria, los vagos de la izquierda NO conocen la vergüenza. NADIE perdió la cabeza así cuando 13.000 estadounidenses murieron de H1N1 en 2010" (White, 2020).

“MSNBC espera que los americanos que mueren por el Coronavirus "derriben la presidencia de Trump” https://t. co/XUBaj6Y8x1 Piensa. Los falsos medios de comunicación quieren que mueras para que eso perjudique al Pres. Trump. Esto es equivalente a la propaganda nazi de Goebbels" (Staub, 2020).

En cambio, tres de ellos se muestran muy críticos con Trump. Se trata de Kurt Eichenwald (@kurteichenwald), periodista y autor de bestsellers de The New York Times; Jim Acosta (@Acosta), Corresponsal Jefe de la Casa Blanca de la CNN y Sarah Jones (@PoliticusSarah), fundadora del medio independiente PoliticusUSA. Algunos ejemplos:

“...es casi incomprensible que el segundo hombre más estúpido del mundo dirija el equipo de Covid-19 para el Gobierno americano, mientras informa al hombre más estúpido del mundo que le dice a todos que no es real, que no es malo, que vayan a trabajar, noticias falsas, engaños, números falsos, etc." (Eichenwald, 2020).

"La respuesta de Trump a la buena pregunta de @acosta sobre las preocupaciones de que no se está tomando el coronavirus lo suficientemente en serio fue llamar a la CNN "noticias falsas". Los encargados de la Casa Blanca inmediatamente obligaron a los reporteros a salir de la habitación. https://t.co/aARJOBHs18” (Rupar, 2020). 


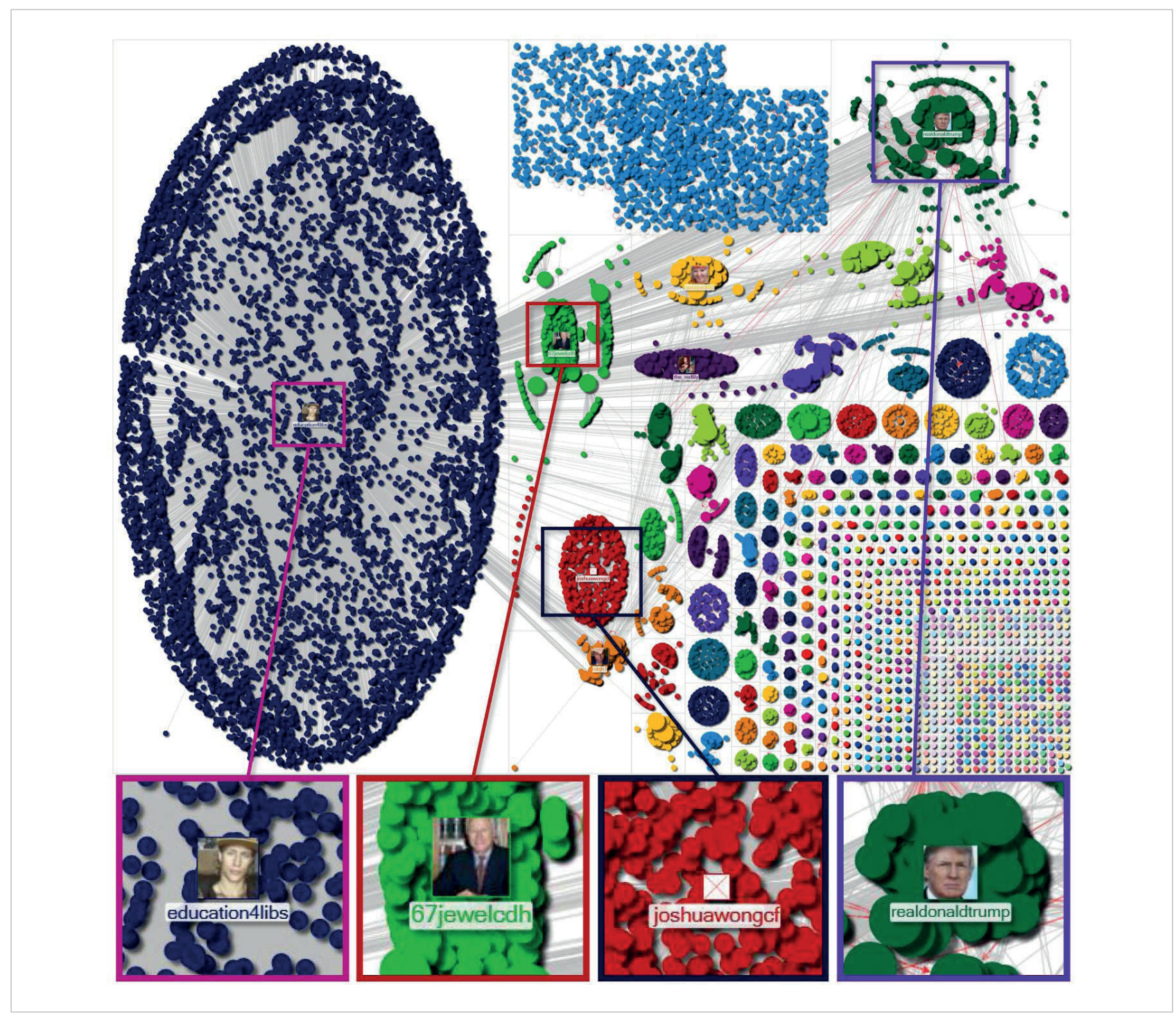

Figura 3. Visualización de los 10 actores más referenciados por los usuarios entre el 23 de enero y el 28 de febrero de 2020

"Esa historia de Vanity Fair que Trump no quiere que leas... "Públicamente, lo ve como otra guerra mediática ("Noticias falsas"); en privado, le preocupan los periodistas portadores de virus en el Air Force One". "Definitivamente se está derritiendo por esto" https://t.co/HCiC1AuDQ4" (Jones, 2020).

Aparte de la lucha entre demócratas y republicanos acusándose mutuamente de publicar noticias falsas sobre el coronavirus, hay otros actores que reciben un gran número de vínculos provenientes de otros usuarios. Uno es Aaron Adajar (@AaronAdajar), fundador de Millennial For Christ, una comunidad centrada en Cristo que escribe tweets en los que recuerda contrastar las noticias, las medidas de higiene y anima a rezar. Otro es el Ministerio de Salud de Brasil (@minsaude), que también recomienda contrastar las informaciones para no alarmar a la población:

"Las noticias falsas son un gran obstáculo en la lucha contra el \#coronavirus (Covid-19). Además de desinformar, pueden generar un alboroto innecesario entre la población. Antes de compartir las noticias, confirme su veracidad. Protégete a ti mismo y a tu familia. Más información

https://t.co/UYm3jliCGA https://t.co/TOjUNGJKXg" (Ministério-da-Saúde, 2020).

Entre los más referenciados también hay que mencionar al medio de comunicación independiente NPR con mensajes como el siguiente:

"El estado de Missouri está demandando al televangelista Jim Bakker y a su compañía de producción para que dejen de anunciar o vender un falso remedio contra el coronavirus. La enfermedad Covid-19 aún no tiene tratamiento ni cura. https://t.co/PPBOzGhU3h" (NPR, 2020).
Jefes de estado como Trump, apoyado en medios de comunicación afines, actuaron de manera irresponsable, convirtiéndose en propagadores de la desinformación 
Tabla 2. Principales actores según el grado de entrada entre el 28 de febrero y el 12 de marzo de 2020

\begin{tabular}{|c|c|c|c|c|}
\hline Cuenta & Nombre & Origen & Entrada & Descripción \\
\hline @realdonaldtrump & Donald Trump & EUA & 4.433 & 45th President of the United States of America. \\
\hline @AaronAdajar & Aaron Adajar & Filipinas & 2.745 & $\begin{array}{l}\text { just a'nobody' with a purpose // @mlnlph. Founder of Millennial For } \\
\text { Christ, a Christ-centered community. }\end{array}$ \\
\hline @kurteichenwald & Kurt Eichenwald & EUA & 2.259 & New York Times bestselling author. \\
\hline @Acosta & Jim Acosta & EUA & 2.037 & $\begin{array}{l}\text { CNN Chief White House Correspondent. Author of NYT Bestseller, } \\
\text { "The Enemy of the People." Winner of NY Press Club "Truth to Power" } \\
\text { award. I believe in \#realnews. }\end{array}$ \\
\hline @minsaude & Ministério da Saúde & Brasil & 1.456 & $\begin{array}{l}\text { Perfil oficial de divulgação de programas, campanhas e relacio- } \\
\text { namento com o usuário. Siga-nos nas redes: http://saude.gov.br/ } \\
\text { redessociais }\end{array}$ \\
\hline$@ N P R$ & $\begin{array}{l}\text { NPR is an independent, } \\
\text { nonprofit media orga- } \\
\text { nization }\end{array}$ & EUA & 874 & $\begin{array}{l}\text { News. Arts \& Life. Music \& more. This is NPR. Securely send us news } \\
\text { tips: http://securedrop.npr.org }\end{array}$ \\
\hline @leandrotessler & Leandro R. Tessler & Brasil & 538 & Físico, professor na Unicamp, editor do Cultura Científica. \\
\hline @USMCSDI & Sean White & EUA & 514 & $\begin{array}{l}\text { \#MAGA \#KAG \#TRUMP2020 \#PROLIFE \#WWG1WGA \#PRO2A \#PRO- } \\
\text { VETERAN \#PROLAWENFORCEMENT } 10 \text { Year Marine Corps veteran. } \\
\text { IFB ALL PATRIOTS (DM me if I don't follow you back). }\end{array}$ \\
\hline @HarveyStaub1 & Harvey Staub & EUA & 341 & $\begin{array}{l}\text { Followed by: \#TheDeplorables, Elmer Fudd; Israel, minorities, Chris- } \\
\text { tians, vets, military, police; \#MAGA \#KAG \#DragonEnergy. }\end{array}$ \\
\hline @PoliticusSarah & Sarah Reese Jones & EUA & 330 & $\begin{array}{l}\text { Boss at One hundred people-powered @PoliticusUSA SAG/AFTRA } \\
\text { "Scandalous trash" Rick Perry *Bookings@politicususa.com. Politi- } \\
\text { cusUSA offers news, commentary, and opinion from a liberal point } \\
\text { of view. PoliticusUSA is independent and is not affiliated with any } \\
\text { political party or organization. }\end{array}$ \\
\hline
\end{tabular}

En lo referente al grado de intermediación, los 10 actores con las posiciones más favorables entre el 23 de enero y el 28 de febrero son casi todos estadounidenses (tabla 3). Son los actores que tienen una mayor capacidad para controlar la difusión de los mensajes sobre los bulos del coronavirus. Se distinguen claramente dos grupos entre estos usuarios que funcionan como intermediarios en las interacciones que dan forma a la red. Un primer grupo gira en torno al sector más conservador de Estados Unidos y está formado por cinco cuentas (@education4libs, @realdonaldtrump, @razorpack65, @robjh1 y @the_redlily) entre las que destaca Donald Trump. El presidente de Estados Unidos, muy dado a la polémica, niega y minimiza durante semanas los efectos de la pandemia y es criticado por el otro grupo, cercano a la

Tabla 3. Principales actores según el grado de intermediación entre el 23 de enero y el 28 de febrero de 2020

\begin{tabular}{|c|c|c|c|c|}
\hline Cuenta & Nombre & Origen & Intermediación & Descripción \\
\hline @education4libs & $\begin{array}{l}\text { Educating Liberals } \\
\text { (Dylan Wheeler) }\end{array}$ & USA & 180.947.403 & $\begin{array}{l}\text { Digital soldier. Followed by @GenFlynn. Mentioned by Q. Retwee- } \\
\text { ted by Trump. Shadowbanned by Twitter. Working on becoming an } \\
\text { independent journalist \#WWG1WGA }\end{array}$ \\
\hline @realdonaldtrump & Donald J. Trump & USA & 49.183.754 & 45th President of the United States of America \\
\hline @67jewelcdh & Carl Hasting & USA & 21.490 .136 & $\begin{array}{l}\text { Tax, transactional \& estate planning attorney. Equality, human righ- } \\
\text { ts, animal rights. We can do better. \#TheResistance \#BlueWave2020 } \\
\text { \#BlackLivesMatter }\end{array}$ \\
\hline @razorpack65 & $\begin{array}{l}\text { Coral (Text Trump } \\
\text { to } 88022)\end{array}$ & USA & 10.180 .903 & Proud American. \\
\hline$@ c n n$ & CNN & USA & 8.896 .409 & $\begin{array}{l}\text { It's our job to \#GoThere \& tell the most difficult stories. Join us! For } \\
\text { more breaking news updates follow @CNNBRK } \\
\text { \& Download our app http://cnn.com/apps }\end{array}$ \\
\hline @lechatnoire4 & $\begin{array}{l}\text { Le Chat Proud } \\
\text { Democrat }\end{array}$ & USA & 8.825 .742 & $\begin{array}{l}\text { \#BLUEWAVE2020 \#BuyARepublicanToday! Trump Making Russia } \\
\text { Great Again. 15th generation American. }\end{array}$ \\
\hline @robjh1 & $\begin{array}{l}\text { Rob Harper. The } \\
\text { Conservative Black } \\
\text { Cowboy }\end{array}$ & USA & 7.853 .653 & $\begin{array}{l}\text { "Vote Red To Save America!" \#BLEXIT } \\
\text { Bandera de Estados Unidos } \\
\text { KAG/ Writer and contributor for http://NewRightNetwork.com and } \\
\text { https://magamedia.org. Arkansas native. }\end{array}$ \\
\hline @the_redlily & Red Lily & USA & 7.320 .785 & $\begin{array}{l}\text { God, guns, family and country. ·Jesus •PATRIOT •MARRIED •NRA } \\
\cdot \text { •BanSHARIA •WWG1WGA •MAGA Ola •FreeGenFlynn •KAG •T2020 } \\
\cdot \text {-GreatAwakening •GodBlessOurTroops }\end{array}$ \\
\hline @patrickdonahue3 & Patrick Donahue & USA & 5.912 .051 & $\begin{array}{l}\text { No one of consequence, if the younger generation is dumb, it's } \\
\text { because we were terrible teachers. Major confession sometimes I } \\
\text { like my own tweets. }\end{array}$ \\
\hline @tjmaruy & $t t r$ & Canada & 5.912 .051 & Hard working. \\
\hline
\end{tabular}




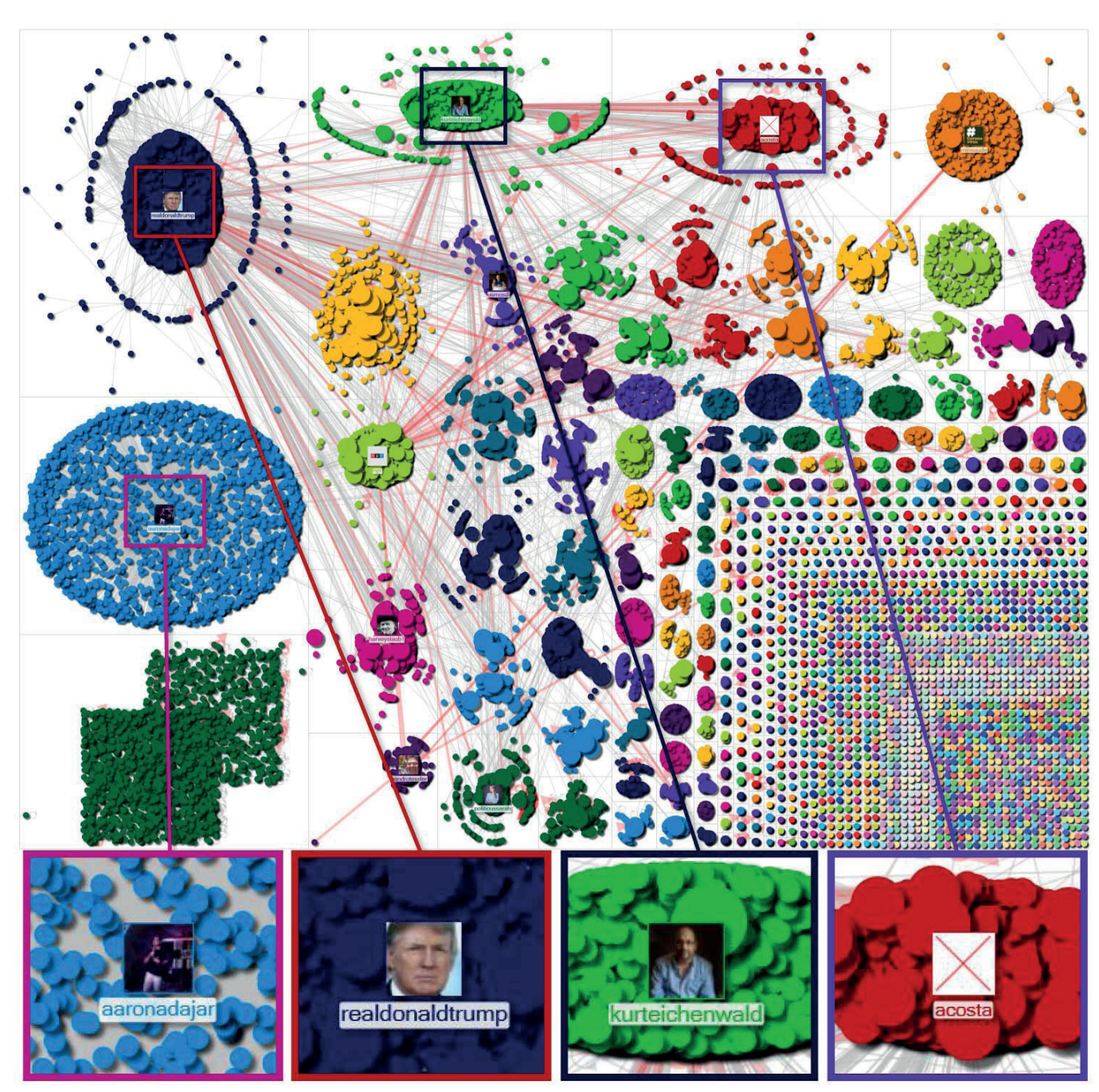

Figura 4. Visualización de los 10 actores más referenciados por los usuarios entre el 28 de febrero y el 12 de marzo de 2020

ideología demócrata, que entiende la gravedad de la situación. Estas cuentas (@67jewelcdh, @cnn, @lechatnoire4, @ patrickdonahue3 y @tjmaruy), entre las que destaca la CNN, también presentan valores muy altos, lo que significa que son puntos de conexión por los que fluye información relevante sobre el coronavirus y pueden ayudar a que se difunda o bloquearla para otras partes de la estructura.

Tras estudiar los patrones de interacción en la red surgida en torno a los bulos sobre el coronavirus, se observa que la situación en Estados Unidos domina la conversación en Twitter esas semanas. La enfermedad ya se había confirmado a principios de febrero, con el primer muerto el 29 de ese mes, pero Trump, en plena campaña electoral para ser reelegido en noviembre, minimiza la situación como si fuese una "simple gripe" durante casi un mes. Twitter se convierte en una herramienta de comunicación política tan importante para Trump en su intento de reelección en 2020 como lo fue en 2016 (Ross; Caldwell, 2020) y pasa esas semanas (junto a sus seguidores) acusando a los medios y a los demócratas de tratar de alimentar la crisis con noticias falsas sobre el coronavirus.

Entre el 28 de febrero y el 12 de marzo se advierten algunos cambios entre los actores que presentan una ventaja estructural en la red. Entre los protagonistas que proporcionan información no redundante disminuye el número de norteamericanos y, como puentes del flujo de información, aparecen en las 10 primeras posiciones usuarios de origen brasileño y filipino. Trump sigue siendo el primero (@realdonaldtrump) pero la situación ha cambiado y sus simpatizantes han desaparecido de los primeros puestos en lo que se refiere al grado de intermediación. En cambio, los norteamericanos críticos a su gestión siguen jugando un papel principal cuando se trata de controlar la difusión de los bulos del coronavirus, como Kurt

A pesar de las acusaciones de pasividad de periodistas y críticos del gobierno de Trump, se observan varias semanas en las que la desinformación distrae de tomar medidas más eficaces y prevenir verdaderamente el contagio 


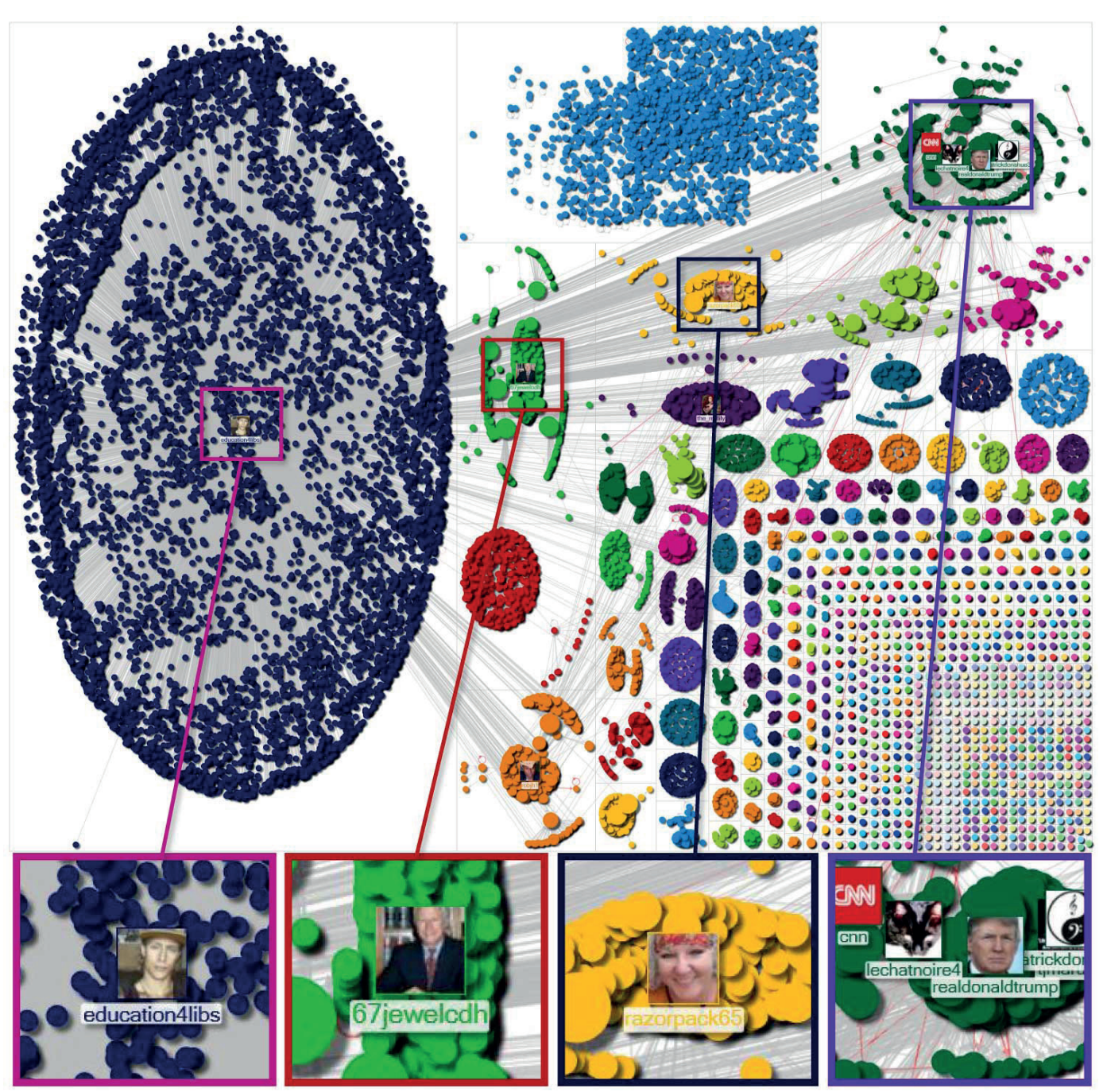

Figura 5. Visualización de los 10 principales actores que funcionan como puentes del flujo de información y controlan la difusión de los bulos del coronavirus entre el 23 de enero y el 28 de febrero de 2020

Eichenwald (@kurteichenwald), periodista y autor de bestsellers de The New York Times; Jim Acosta (@Acosta), Corresponsal Jefe de la Casa Blanca de la CNN y el medio independiente NPR (@NPR).

Durante esas dos semanas, aumenta el número de usuarios (entre las posiciones más favorables en la red) que hablan sobre las medidas de higiene para prevenir la pandemia y la necesidad de estar alerta ante los bulos que están inundando el escenario informativo. Destacan dos cuentas de Filipinas, @NakPapaMoto_y @AaronAdajar, que son dos de los puntos de conexión por los que fluye información relevante y que, en esta ocasión, van a ayudar a difundir hacia otras partes de la red la idea de contrastar la información sobre el coronavirus antes de reenviarla a terceros. Además, recuerdan varias medidas de higiene personal y alientan a rezar.

"Isa sa pinakamaganda mong maa-ambag sobre el brote de Covid-19 ay "pananahimik". Deja de difundir noticias falsas e investiga primero antes de publicar algo en Internet. Y también, lávate las manos intensamente. Evita tocarte la cara. Reza. Reza. Reza. Reza." (Adajar, 2020).

En la misma línea aparecen varios nodos procedentes de Brasil, entre los que sobresale el Ministerio de Salud (@minsaude) de dicho país. Este cambio, en un periodo tan corto, en los actores que presentan una ventaja estructural en la red es un reflejo de lo ocurrido esas semanas, en la que los bulos sobre el coronavirus se convierten en otra epidemia. Son perfiles con un grado de intermediación alto, lo que significa que gran cantidad de información no redundante pasa a través de ellos. Estos nuevos actores hacen un llamamiento a los usuarios para parar las fake news y recuerdan que solo puede hacerse con su ayuda.

Aunque Italia y España han sido unos de los países más afectados por esta crisis después de China, las conversaciones y actores procedentes de estos países no cobran la relevancia esperada 
Tabla 4. Principales actores según el grado de intermediación entre el 28 de febrero y el 12 de marzo de 2020

\begin{tabular}{|c|c|c|c|c|}
\hline Cuenta & Nombre & Origen & Intermediación & Descripción \\
\hline @realdonaldtrump & Donald Trump & EUA & 37.168 .7615 & 45th President of the United States of America. \\
\hline @kurteichenwald & Kurt Eichenwald & EUA & 27.3633 .207 & The New York Times bestselling author. \\
\hline @NakPapaMoto_ & Papa & Filipinas & 161.866 .944 & Ang Pambansang PAPA (The National PAPA) \\
\hline @still_lany & dramatic bitch & EUA & 160.111 .960 & $\begin{array}{l}\text { lol ur not paul klein. Follower of LANY, an American indie pop } \\
\text { band from Los Angeles }\end{array}$ \\
\hline @AaronAdajar & Aaron Adajar & Filipinas & 140.972 .528 & $\begin{array}{l}\text { just a 'nobody' with a purpose // @mlnlph. Founder of Millennial } \\
\text { For Christ, a Christ-centered community. }\end{array}$ \\
\hline @Acosta & Jim Acosta & EUA & 138.260 .397 & $\begin{array}{l}\text { CNN Chief White House Correspondent. Author of NYT Bestseller, } \\
\text { "The Enemy of the People." Winner of NY Press Club "Truth to } \\
\text { Power" award. I believe in \#realnews. }\end{array}$ \\
\hline @minsaude & Ministério da Saúde & Brasil & 88.971 .604 & $\begin{array}{l}\text { Perfil oficial de divulgação de programas, campanhas e relaciona- } \\
\text { mento com o usuário. Siga-nos nas redes: } \\
\text { http://saude.gov.br/redessociais }\end{array}$ \\
\hline @NPR & $\begin{array}{l}\text { NPR is an indepen- } \\
\text { dent, nonprofit } \\
\text { media organization }\end{array}$ & EUA & 63.361 .147 & $\begin{array}{l}\text { News. Arts \& Life. Music \& more. This is NPR. Securely send us } \\
\text { news tips: } \\
\text { http://securedrop.npr.org }\end{array}$ \\
\hline @FilLeal & Fil Leal & Brasil & 40.866 .154 & $\begin{array}{l}\text { Civil Engineer. Nao se espante se no lugar em que se alardeia } \\
\text { ética como bordão, ética for o que mais está faltando. }\end{array}$ \\
\hline @nah_sabba & Nah_Sabba & Brasil & 40.866 .154 & $\begin{array}{l}\text { Foco, Força, Fé, Farofa, Feijão ... não péra. (Focus, Strength, Faith, } \\
\text { Farofa, Beans ... don't worry ..). }\end{array}$ \\
\hline
\end{tabular}

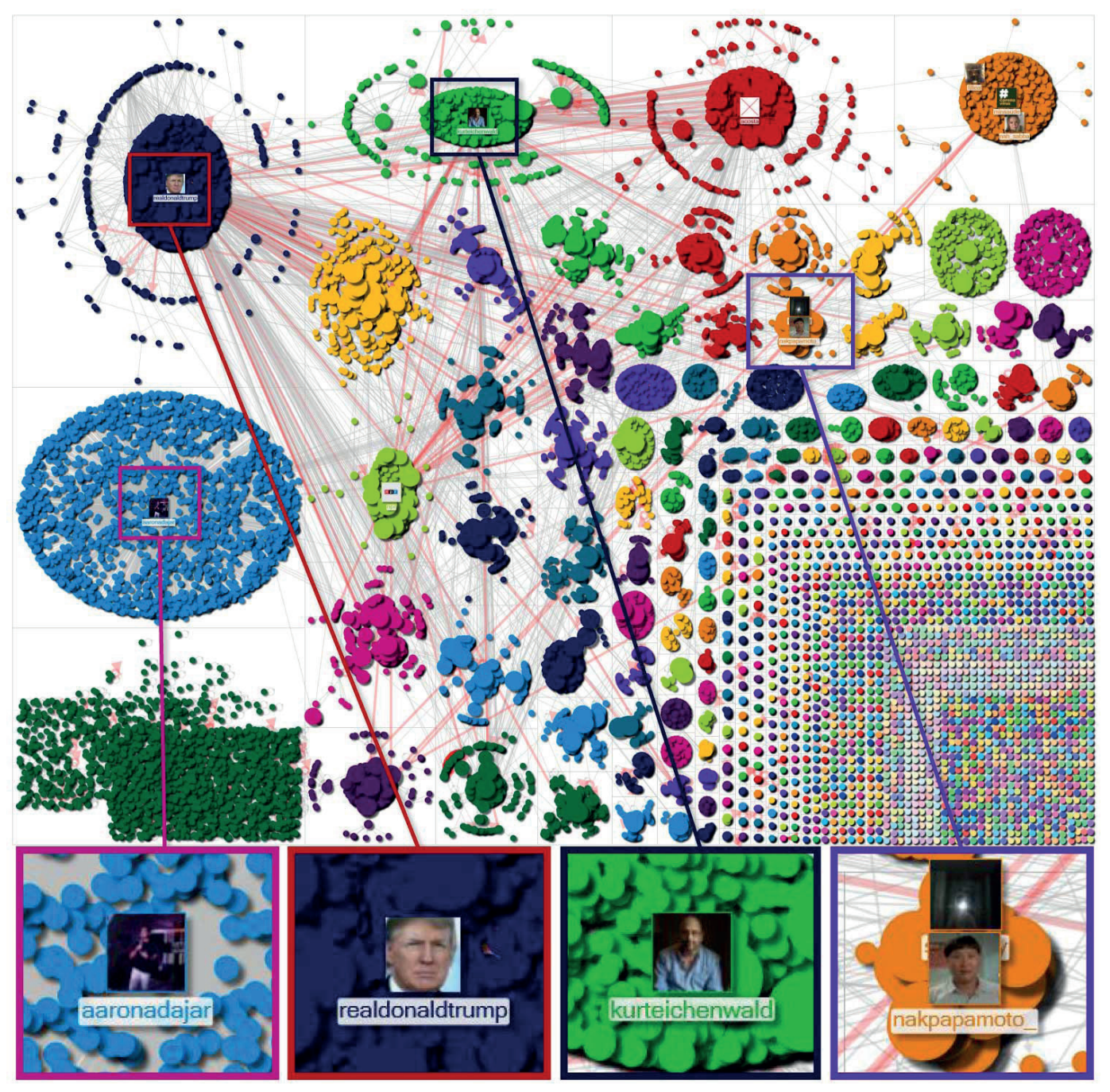

Figura 6. Visualización de los 10 principales actores que funcionan como puentes del flujo de información y controlan la difusión de los bulos del coronavirus entre el 28 de febrero y el 12 de marzo de 2020 


\subsection{Análisis semántico de la red}

El hilo de conversación más importante entre el 23 de enero y el 28 de febrero (ver figura 7) hace referencia al desplome del mercado de valores en Estados Unidos ( 27 de febrero) por el temor al coronavirus, la peor caída desde la crisis financiera de 2008. Es un tema muy popular entre los defensores de Donald Trump que echan la culpa a los medios de comunicación embusteros (fake news media). Según ellos, estos medios, simpatizantes de los demócratas como la CNN, exageran el peligro del Covid-19 para asustar al público con sus informaciones y perjudicar a Trump antes de las elecciones. La segunda asociación más significativa, a gran distancia de la anterior, es crítica con la postura mantenida por el presidente estadounidense. Son usuarios que están preocupados porque hay un sector de la población en los que ha calado hondo el mensaje de Trump y medios afines como la Fox.

Dos semanas después, las conversaciones más relevantes en torno a las noticias falsas (ver figura 8) están asociadas con dos medios de comunicación a los que Trump y sus seguidores acusan de mentir. El primer medio asociado con las fake news es la revista Vanity Fair cuyo artículo publicado el 9 de marzo (Sherman, 2020) no va a gustar al presidente estadounidense. Éste va a tildar en Twitter a sus periodistas de inventarse las fuentes y de ser reporteros de tercera categoría, además de avisar a la revista de que "pronto dejará de existir". La segunda conexión es con la CNN y está relacionada con la pregunta realizada a Donald Trump el 11 de marzo por el corresponsal jefe de la Casa Blanca de la cadena. Trump descartó la pregunta sobre el coronavirus de Jim Acosta de la CNN calificándola como "noticia falsa" y le invitó a salir de la habitación. La segunda asociación de palabras presente en los tweets apela a la necesidad de comprobar la veracidad de las noticias antes de compartirlas (stop + spreading) y se completa con una llamada a lavarse las manos (wash + hands) y evitar tocarse la cara (avoid + touching + face). El aumento de la presencia de estos temas a finales de febrero es un reflejo de la preocupación ante la tardanza en adoptar medidas de prevención e higiene que frenen la expansión del coronavirus (lo que condujo a la OMS a declarar el 12 de marzo el brote de coronavirus como pandemia global).

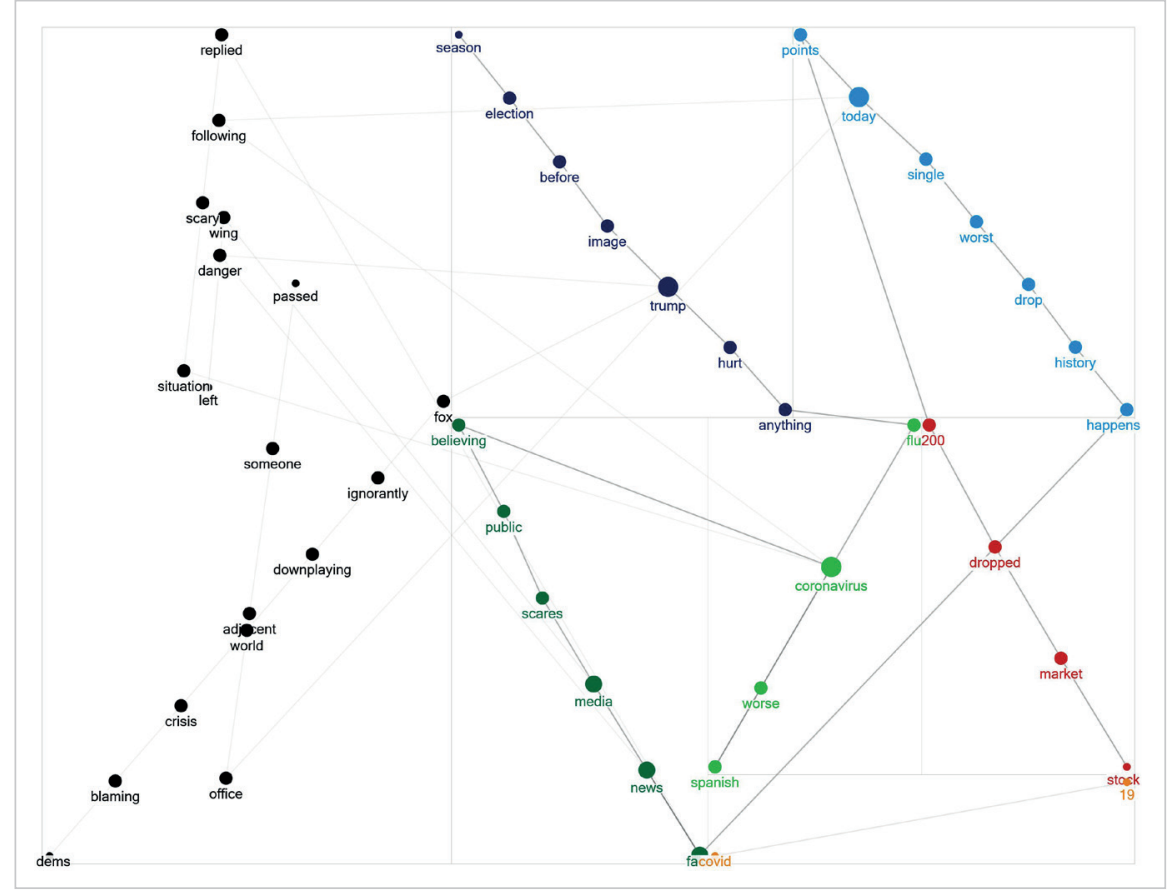

Figura 7. Representación de los temas de conversación más relevantes en torno a las noticias falsas sobre el coronavirus entre el 23 de enero y el 28 de febrero de 2020

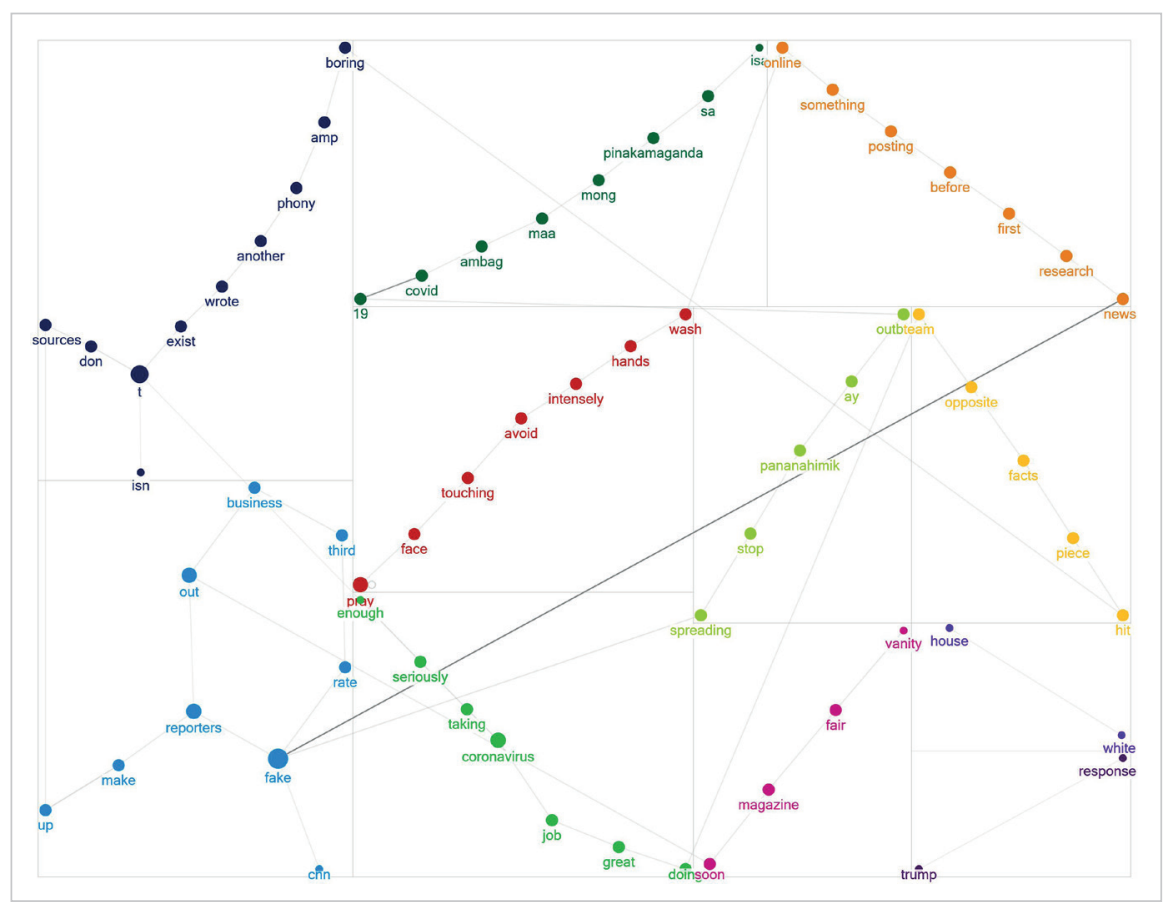

Figura 8. Representación de los temas de conversación más relevantes en torno a las noticias falsas sobre el coronavirus entre el 28 de febrero y el 12 de marzo de 2020 


\section{Conclusiones}

La investigación recoge la guerra mediática desatada entre republicanos y demócratas a raíz de la expansión del Covid-19. Entre los actores que presentan mayor ventaja estructural en la red hay que señalar a Donald Trump, que se convierte en protagonista de gran parte de los mensajes. Este estudio muestra el estado de negación que vive la Casa Blanca esas semanas, calificándola de "simple gripe" durante casi un mes, a pesar de que la enfermedad se detectó a principios de febrero en Estados Unidos.

La consecuencia de esto es que, si consideramos la red en términos de grado de entrada, los actores que reciben más vínculos provenientes de otros usuarios (y que ven como sus contenidos son los más referenciados y viralizados) están relacionados con la pugna entre demócratas y republicanos. Simpatizantes de ambos bandos se acusan mutuamente de mentir sobre el coronavirus y acusan en sus mensajes a periodistas y medios de comunicación como la CNN, Fox o Vanity Fair de publicar noticias falsas. Los resultados muestran un cambio entre el 28 de febrero y el 12 de marzo ante el avance imparable del coronavirus. Aparecen en segundo lugar nuevos actores entre los más influyentes, como el Ministério da Saúde do Brasil, cuyas publicaciones recuerdan la necesidad de contrastar las informaciones antes de difundirlas y también inciden en las medidas de higiene a adoptar.

Si consideramos el grado de intermediación, las primeras semanas los nodos con posiciones más favorables en la red y que poseen la mayor capacidad para controlar la difusión de los mensajes sobre los bulos del coronavirus, son todos americanos. A pesar de que Europa se ha convertido en el epicentro global del Covid-19, se observa que el cruce de acusaciones en Estados Unidos domina la conversación en Twitter. El más importante entre los actores que proporcionan información no redundante es Donald Trump, que mantiene que el coronavirus no es un problema en EUA y pasa esas semanas (junto a sus seguidores) acusando a los medios y a los demócratas de mentir. A partir del 28 de febrero, varios usuarios brasileños y filipinos sustituyen a parte de los actores norteamericanos. Funcionan como intermediarios en las conversaciones entre los usuarios que dan forma a la red y difunden información diferente que no tiene que ver con la política estadounidense.

En efecto, el análisis semántico recoge cómo a partir de finales de febrero las referencias a las medidas de prevención e higiene para contener la propagación del virus escalan posiciones entre los términos con conexiones más fuertes. Entre estas medidas destaca la de contrastar las informaciones falsas. La crisis de Covid-19 pasa a ser también, además de una crisis de salud pública y una crisis económica, una crisis de información. El estudio detecta desde ese momento una reacción ante la avalancha de rumores sobre cómo frenar la expansión del virus. Los bulos se han convertido en otra epidemia y la preocupación por verificar las noticias antes de difundirlas aparece entre los contenidos predominantes. Piden la ayuda de los usuarios para pararlos.

Para concluir y a modo de resumen, hay que apuntar que se cumple $\mathrm{H} 1$ porque desde el primer momento se observa que la presencia de expertos entre los nodos con posiciones más favorables en la red es muy reducida. Básicamente son periodistas y medios de comunicación norteamericanos simpatizantes de los demócratas. A finales de febrero aparece algún experto más entre los primeros puestos. No obstante, siguen siendo pocos. En general, se echa en falta una mayor presencia de científicos, expertos e instituciones que den su opinión sobre las medidas de salud y ayuden a desmentir los bulos. En esta crisis, incluso las propias autoridades en las que la gente confía demuestran una alarmante falta de información. Jefes de estado como Trump, apoyado en medios de comunicación afines, actuaron de manera irresponsable, convirtiéndose en propagadores de esa desinformación.

La segunda hipótesis $(\mathrm{H} 2)$ solo se cumple en la primera mitad del periodo de estudio. A pesar de las denuncias de pasividad de periodistas y críticos del gobierno de Trump, se observan varias semanas de conversación en las que la desinformación distrae de tomar medidas más eficaces y prevenir verdaderamente el contagio. A finales de febrero ya no se cumple $\mathrm{H} 2$ porque cobran importancia los hilos de conversación que se centran en desmentir los bulos sobre el coronavirus con un objetivo de educar e informar.

Tampoco se cumple H3 ya que, aunque Italia y España han sido unos de los países más afectados por esta crisis después de China, las conversaciones y actores procedentes de estos países no cobran la relevancia esperada. EUA y su presidente Donald Trump se consagran una vez más como actores relevantes, no únicamente como potencia mundial a nivel político y económico, sino en las conversaciones y en la influencia que éstas tienen en la red y, en este caso, en Twitter.

\section{Referencias}

Adajar, Aaron (2020). Aaron Adajar on Twitter: «Isa sa pinakamaganda mong maa-ambag about Covid-19 outbreak ay "pananahimik" Stop spreading fake news and do research first before posting something online. And also, Wash your hands intensely. Avoid touching your face. Pray. Pray. Pray». Twitter, March 9.

https://twitter.com/aaronadajar/status/1237029903112888321 
Aguilar-Gallegos, Norman; Martínez-González, Enrique-Genaro; Aguilar-Ávila, Jorge; Santoyo-Cortés, Horacio; Muñoz-Rodríguez, Manrrubio; García-Sánchez, Edgar-Iván (2016). “Análisis de redes sociales para catalizar la innovación agrícola: De los vínculos directos a la integración y radialidad”. Estudios gerenciales, v. 32, n. 140, pp. 197-207. https://doi.org/10.1016/j.estger.2016.06.006

Ahmed, Wasim; Lugovic, Sergej (2019). "Social media analytics: Analysis and visualisation of news diffusion using NodeXL. Online information review", v. 43, n. 1, pp. 149-160.

https://doi.org/10.1108/OIR-03-2018-0093

Albalawi, Yahya; Nikolov, Nikola S.; Buckley, Jim (2019). "Trustworthy health-related tweets on social media in Saudi Arabia: Tweet metadata analysis". Journal of medical internet research, v. 21, n. 10, e14731. https://doi.org/10.2196/14731

Allcott, Hunt; Gentzkow, Matthew (2017). "Social media and fake news in the 2016 election". Journal of economic perspectives, v. 31, n. 2, pp. 211-236.

https://doi.org/10.1257/jep.31.2.211

Araujo, Matheus; Mejova, Yelena; Weber, Ingmar; Benevenuto, Fabrizio (2017). "Using Facebook ads audiences for global lifestyle disease surveillance: Promises and limitations". In: Proceedings of the 2017 ACM on Web science conference, pp. 253-257.

https://doi.org/10.1145/3091478.3091513

Bae, Ka-Ryeong; Kwon, Sunyoung; Cho, Juhee (2019). "What cancer survivors are discussing on the internet about returning to work: A social network analysis". Asian oncology nursing, v. 19, n. 1, pp. 37-46. https://doi.org/10.5388/aon.2019.19.1.37

Bakal, Gotkhan; Kavuluru, Ramakanth (2017). "On quantifying diffusion of health information on Twitter". 2017 IEEE EMBS International conference on biomedical \& health informatics (BHI), pp. 485-488.

https://doi.org/10.1109/BHI.2017.7897311

Bakshy, Eytan; Hofman, Jake M.; Mason, Winter A.; Watts, Duncan J. (2011). "Everyone's an influencer: Quantifying influence on Twitter". Proceedings of the Fourth ACM International conference on web search and data mining - WSDM '11, pp. 65-74.

https://doi.org/10.1145/1935826.1935845

Benson, Phil (2016). The discourse of YouTube: Multimodal text in a global context. Routledge. https://doi.org/10.4324/9781315646473

Berkowitz, Dan; Schwartz, David-Asa (2016). "Miley, CNN and The Onion: When fake news becomes realer than real". Journalism practice, v. 10, n. 1, pp. 1-17.

https://doi.org/10.1080/17512786.2015.1006933

Borgatti, Stephen P.; Mehra, Ajay; Brass, Daniel J.; Labianca, Giuseppe (2009). "Network analysis in the social sciences". Science, v. 323, n. 5916, pp. 892-895 https://doi.org/10.1126/science.1165821

Boyd, Michael S. (2014). "(New) participatory framework on YouTube? Commenter interaction in US political speeches". Journal of pragmatics, v. 72, pp. 46-58.

https://doi.org/10.1016/j.pragma.2014.03.002

Broniatowski, David A.; Jamison, Amelia M.; Qi, Sihua; AlKulaib, Lulwah; Chen, Tao; Benton, Adrian; Quinn, Sandra C.; Dredze, Mark (2018). "Weaponized health communication: Twitter bots and Russian trolls amplify the vaccine debate". American journal of public health, v. 108, n. 10, pp. 1378-1384.

https://doi.org/10.2105/AJPH.2018.304567

Brubaker, Pamela-Jo; Wilson, Christopher (2018). "Let's give them something to talk about: Global brands' use of visual content to drive engagement and build relationships". Public relations review, v. 44, n. 3, pp. 342-352.

https://doi.org/10.1016/j.pubrev.2018.04.010

Cheng, Tiffany Yi-Mei; Liu, Lisa; Woo, Benjamin K. (2018). "Analyzing Twitter as a platform for Alzheimer-related dementia awareness: Thematic analyses of tweets". JMIR aging, v. 1, n. 2, e11542.

https://doi.org/10.2196/11542

Chu, Zi; Gianvecchio, Steven; Wang, Haining; Jajodia, Sushil (2012). “Detecting automation of Twitter accounts: Are you a human, bot, or cyborg?". IEEE Transactions on dependable and secure computing, v. 9, n. 6, pp. 811-824.

https://doi.org/10.1109/TDSC.2012.75 
Chung, Chia-Fang; Agapie, Elena; Schroeder, Jessica; Mishra, Sonali; Fogarty, James; Munson, Sean A. (2017). "When personal tracking becomes social: Examining the use of Instagram for healthy eating". Proceedings of the $2017 \mathrm{CHI}$ Conference on human factors in computing systems, pp. 1674-1687.

https://doi.org/10.1145/3025453.3025747

Clauset, Aaron; Newman, Mark E. J.; Moore, Cristopher (2004). "Finding community structure in very large networks". Physical review E, v. 70, n. 6, pp. 66-111.

https://doi.org/10.1103/PhysRevE.70.066111

Cosentino, Gabriele (2020). “Polarize and conquer: Russian influence operations in the United States”. In: Cosentino, Gabriele. Social media and the post-truth world order. Springer International Publishing, pp. 33-57. ISBN: 9783030430054 https://doi.org/10.1007/978-3-030-43005-4_2

Currie-Sivek, Susan; Bloyd-Peshkin, Sharon (2018). “Where do facts matter?: The digital paradox in magazines' fact-checking practices". Journalism practice, v. 12, n. 4, pp. 400-421.

https://doi.org/10.1080/17512786.2017.1307694

Dossis, Michael; Amanatidis, Dimitrios; Mylona, Ifigeneia (2015). “Mining Twitter data: Case studies with trending hashtags". In: Proceedings in ARSA-Advanced research in scientific areas, 4th Virtual international conference on advanced research in scientific areas (ARSA), Slovakia, pp. 242-246.

https://doi.org/10.18638/arsa.2015.4.1.751

Dredze, Mark; Broniatowski, David A.; Hilyard, Karen M. (2016). "Zika vaccine misconceptions: A social media analysis". Vaccine, v. 34, n. 30, pp. 3441-3442.

https://doi.org/10.1016/j.vaccine.2016.05.008

Eichenwald, Kurt (2020). Kurt Eichenwald on Twitter: "...It is almost incomprehensible that the second stupidest man in the world is leading the Covid-19 team for the American government, while reporting to the stupidest man in the world who tells everyone it isn't real, it isn't bad, go to work, fake news, hoax, fake numbers, etc.". Twitter, March 7. https://twitter.com/kurteichenwald/status/1236068998883741696

Evans, Matt (2016). "Information dissemination in new media: YouTube and the Israeli-Palestinian conflict". Media, war \& conflict, v. 9, n. 3, pp. 325-343.

https://doi.org/10.1177/1750635216643113

Fernández, Deborah (2019). “Análisis de grafos en redes sociales: Medidas de centralidad”. Datahack, 19 agosto. https://www.datahack.es/grafos-redes-sociales-centralidad

Fox, Susannah (2011). "The social life of health information, 2011". Pew Research Center: Internet, science \& tech, 12 May. https://www.pewresearch.org/internet/2011/05/12/the-social-life-of-health-information-2011

Freeman, Linton C. (2004). "The development of social network analysis". A study in the sociology of science, v. 1, p. 687. ISBN: 9781594577147

Frish, Yael; Greenbaum, Dov (2017). "Is social media a cesspool of misinformation? Clearing a path for patient-friendly safe spaces online". The American journal of bioethics, v. 17, n. 3, pp. 19-21.

https://doi.org/10.1080/15265161.2016.1274795

Ghenai, Amira; Mejova, Yelena (2017). "Catching Zika fever: Application of crowdsourcing and machine learning for tracking health misinformation on Twitter". 2017 IEEE International conference on healthcare informatics (ICHI), pp. 518-518.

https://doi.org/10.1109/ICHI.2017.58

Ghenai, Amira; Mejova, Yelena (2018). "Fake cures: User-centric modeling of health misinformation in social media". Proceedings of the ACM on human-computer interaction, 2 (CSCW), pp. 1-20.

https://doi.org/10.1145/3274327

Gibbs, William J.; McKendrick, Joseph (eds.). (2015). Contemporary research methods and data analytics in the news industry. Hershey, PA: IGI Global.

https://doi.org/10.4018/978-1-4666-8580-2

Gonçalves-Sá, Joana (2020). "In the fight against the new coronavirus outbreak, we must also struggle with human bias". Nature medicine, v. 26, n. 3, pp. 305-305.

https://doi.org/10.1038/s41591-020-0802-y

Gu, Rui; Hong, Yili-Kevin (2019). “Addressing health misinformation dissemination on mobile social media”. In: 2019 ICIS Conference.

https://aisel.aisnet.org/icis2019/is_health/is_health/29 
Gueham, Farid (2017). Le fact-checking: une réponse à la crise de l'information et de la démocratie. Paris: Fondation pour l'innovation politique.

http://www.fondapol.org/wp-content/uploads/2017/07/1110-Fact-checking_2017-07-10_web.pdf

Guidry, Jeanine P. D.; Jin, Yan; Orr, Caroline A.; Messner, Marcus; Meganck, Shana (2017). "Ebola on Instagram and Twitter: How health organizations address the health crisis in their social media engagement". Public relations review, $\mathrm{v}$. 43, n. 3, pp. 477-486.

https://doi.org/10.1016/j.pubrev.2017.04.009

Hansen, Derek; Shneiderman, Ben; Smith, Marc A. (2010). Analyzing social media networks with NodeXL: Insights from a connected world. Morgan Kaufmann. ISBN: 9780123822291

Harel, David; Koren, Yehuda (2000). "A fast multi-scale method for drawing large graphs". Proceedings of the Working conference on advanced visual interfaces - AVI'00, pp. 282-285.

https://doi.org/10.1145/345513.345353

Harper, Rob (2020). @robjh1: The Conservative Black Cowboy on Twitter: "Rush Limbaugh and AG Bill Barr call out the left wing media. The left wing media has become agents of division and anarchy. Instead of informing they seek to attack and destroy with fake news. \#\#FakeNewsMedia \#coronavirus". Twitter.

https://twitter.com/robjh1/status/1233266971237593088

Hasting, Carl (2020). Carl Hasting on Twitter: "I passed someone from an adjacent office today and said, "Are you following this Coronavirus situation? Scary." She replied, "Fake news!" And there you have the danger of Trump and Fox ignorantly downplaying a world crisis and blaming it on the Dems". Twitter, February 27.

https://twitter.com/67jewelcdh/status/1232885944623063040

Herchel-Thaddeus, Machacon (2016). "A topological data analysis approach to visualizing Ebola tweets". Japan journal for medical informatics, v. 36, n. 5, pp. 253-269.

https://doi.org/10.14948/jami.36.253

Himelboim, Itai; Han, Jeong-Yeob (2014). "Cancer talk on Twitter: Community structure and information sources in breast and prostate cancer social networks". Journal of health communication, v. 19, n. 2, pp. 210-225.

https://doi.org/10.1080/10810730.2013.811321

Hou, Rui; Pérez-Rosas, Verónica; Loeb, Stacy; Mihalcea, Rada (2019). “Towards automatic detection of misinformation in online medical videos". In: 2019 International conference on multimodal interaction, pp. 235-243.

https://arxiv.org/abs/1909.01543

Jamison, Amelia M.; Broniatowski, David A.; Quinn, Sandra-Crouse (2019). “Malicious actors on Twitter: A guide for public health researchers". American journal of public health, v. 109, n. 5, pp. 688-692.

https://doi.org/10.2105/AJPH.2019.304969

Javanainen, Petra-Marika (2020). The role of social media in attitudes towards vaccinations: Social media as a tool in vaccination movements.

http://www.theseus.fi/handle/10024/334093

Jones, Sarah (2020). Sarah Reese Jones on Twitter: "That Vanity Fair story Trump doesn't want you to read... "Publicly, he sees it as yet another ("Fake news») media war; privately, he worries about virus-carrying journalists on Air Force One" "He's Definitely Melting Down Over This". Twitter, March 11.

https://twitter.com/politicussarah/status/1237778298530344961

Kaleel, Shakira-Banu; Abhari, Abdolreza (2015). "Cluster-discovery of Twitter messages for event detection and trending". Journal of computational science, v. 6, pp. 47-57.

https://doi.org/10.1016/j.jocs.2014.11.004

Kata, Anna (2012). "Anti-vaccine activists, Web 2.0, and the postmodern paradigm - An overview of tactics and tropes used online by the anti-vaccination movement". Vaccine, v. 30, n. 25, pp. 3778-3789.

https://doi.org/10.1016/j.vaccine.2011.11.112

Laylavi, Farhad; Rajabifard, Abbas; Kalantari, Mohsen (2017). “Event relatedness assessment of Twitter messages for emergency response". Information processing \& management, v. 53, n. 1, pp. 266-280.

https://doi.org/10.1016/j.ipm.2016.09.002

Leonhardt, James (2015). "Going viral on YouTube”. Journal of digital \& social media marketing, v. 3, n. 1, pp. 21-30.

https://www.ingentaconnect.com/content/hsp/jdsmm/2015/00000003/00000001/art00004 
Lichoti, Jacqueline-Kasiiti; Davies, Jocelyn; Kitala, Philip M.; Githigia, Samuel M.; Okoth, Edward; Maru, Yiheyis; Bukachi, Salome A.; Bishop, Richard P. (2016). "Social network analysis provides insights into African swine fever epidemiology". Preventive veterinary medicine, v. 126, pp. 1-10.

https://doi.org/10.1016/j.prevetmed.2016.01.019

Lipschultz, Jeremy-Harris (2017). Social media communication: Concepts, practices, data, law and ethics ( $2^{\text {nd }}$ ed.). New York: Routledge. ISBN: 9781315388144

https://doi.org/10.4324/9781315388144

Mejova, Yelena; Haddadi, Hamed; Abbar, Sofiane; Ghahghaei, Azadeh; Weber, Ingmar (2015). "Dietary habits of an expat nation: Case of Qatar". In: Healthcare Informatics (ICHI), 215 International Conference on. IEEE, pp. 57-62. https://doi.org/ 10.1109/ICHI.2015.13.

Ministério da Saúde da Brasil (2020). Ministério da Saúde on Twitter: “As fake news são um grande obstáculo no combate ao \#coronavírus (Covid-19). Além de desinformar, elas podem gerar um alarde desnecessário entre a população. Antes de compartilhar notícias, confirme a veracidade delas. Proteja você e sua família. Saiba mais“. Twitter, Março 4.

https://twitter.com/minsaude/status/1235007050159190016

Mohr, Iris (2014). "Going viral: An analysis of YouTube videos". Journal of marketing development and competitiveness, v. 8, n. 3, pp. 43-48.

http://na-businesspress.homestead.com/JMDC/Mohrl_Web8_3_.pdf

Moorhead, S. Anne; Hazlett, Diane E.; Harrison, Laura; Carroll, Jennifer K.; Irwin, Anthea; Hoving, Ciska (2013). “A new dimension of health care: Systematic review of the uses, benefits, and limitations of social media for health communication". Journal of medical internet research, v. 15, n. 4, e85.

https://doi.org/10.2196/jmir.1933

NPR (2020). NPR on Twitter: "The state of Missouri is suing televangelist Jim Bakker and his production company to stop them from advertising or selling a fake coronavirus remedy. The Covid-19 disease does not yet have a treatment or cure". Twitter, March 12.

https://twitter.com/npr/status/1238014380526186499

Odlum, Michelle; Yoon, Sunmoo (2015). "What can we learn about the Ebola outbreak from tweets?". American journal of infection control, v. 43, n. 6, pp. 563-571.

https://doi.org/10.1016/j.ajic.2015.02.023

Otte, Evelien; Rousseau, Ronald (2002). "Social network analysis: A powerful strategy, also for the information sciences". Journal of information science, v. 28, n. 6, pp. 441-453.

Paolillo, John C. (2008). Structure and network in the YouTube core. Proceedings of the $41^{\text {st }}$ Annual Hawaii international conference on system sciences (HICSS 2008), pp. 156-156.

https://doi.org/10.1109/HICSS.2008.415

Park, Se-Jung; Lim, Yon-Soo; Park, Han-Woo (2015). "Comparing Twitter and YouTube networks in information diffusion: The case of the 'Occupy Wall Street' movement". Technological forecasting and social change, v. 95, pp. $208-217$.

https://doi.org/10.1016/j.techfore.2015.02.003

Pauner-Chulvi, Cristina (2018). “Noticias falsas y libertad de expresión e información. El control de los contenidos informativos en la red". Teoría y realidad constitucional, n. 41, pp. 297-318.

https://doi.org/10.5944/trc.41.2018.22123

Ross, Andrew S.; Caldwell, David (2020). “'Going negative': An appraisal analysis of the rhetoric of Donald Trump on Twitter". Language \& communication, n. 70, pp. 13-27.

https://doi.org/10.1016/j.langcom.2019.09.003

Rupar, Aaron (2020). Aaron Rupar on Twitter: “Trump's response to @acosta's good question about concerns he isn't taking coronavirus seriously enough was to call CNN 'fake news'. White House handlers then immediately forced reporters out of the room". Twitter, March 11.

https://twitter.com/atrupar/status/1237875754576146445

Scanfeld, Daniel; Scanfeld, Vanessa; Larson, Elaine L. (2010). “Dissemination of health information through social networks: Twitter and antibiotics". American journal of infection control, v. 38, n. 3, pp. 182-188.

https://doi.org/10.1016/j.ajic.2009.11.004

Scott, John; Carrington, Peter (2014). The SAGE Handbook of social network analysis. London: SAGE Publications Ltd. ISBN: 9781847873958.

https://doi.org/10.4135/9781446294413 
Seo, Sungwon; Kim, Jong-Kook; Kim, Sung-II; Kim, Jeewoo; Kim, Joongheon (2019). "Semantic hashtag relation classification using co-occurrence word information". Wireless personal communications, v. 107, n. 3, pp. 1355-1365. https://doi.org/10.1007/s11277-018-5745-y

Shao, Chengcheng; Hui, Pik-Mai; Wang, Lei; Jiang, Xinwen; Flammini, Alessandro; Menczer, Filippo; Ciampaglia, Giovanni-Luca (2018). "Anatomy of an online misinformation network". PLoS one, v. 13, n. 4, e0196087. https://doi.org/10.1371/journal.pone.0196087

Sharevski, Filipo; Jachim, Peter; Florek, Kevin (2020). "To tweet or not to tweet: Covertly manipulating a Twitter debate on vaccines using malware-induced misperceptions". arXiv:2003.12093 [cs].

http://arxiv.org/abs/2003.12093

Sherman, Gabriel (2020). "He's definitely melting down over this: Trump, germaphobe in chief, struggles to control the Covid-19 story". Vanity fair, 9 March.

https://www.vanityfair.com/news/2020/03/trump-germaphobe-in-chief-struggles-to-control-the-covid-19-story

Shu, Kai; Sliva, Amy; Wang, Suhang; Tang, Jiliang; Liu, Huan (2017). "Fake news detection on social media: A data mining perspective". ACM SIGKDD Explorations newsletter, v. 19, n. 1, pp. 22-36.

https://doi.org/10.1145/3137597.3137600

Skeptical7th (2019). "Fact checking 'Educating liberals' aka Dylan Wheeler". The seventh degree.

https://www.theseventhdegree.net/news/2018/11/3/fact-checking-educating-liberals

Smith, Marc; Milic-Frayling, Natasa; Shneiderman, Ben; Mendes-Rodrigues, Eduarda; Leskovec, Jure; Dunne, Cody (2010). NodeXL: A free and open network overview, discovery and exploration add-in for Excel 2007/2010. Social Media Research Foundation.

https://www.smrfoundation.org

Staub, Harvey (2020). Harvey Staub on Twitter: "MSNBC Hopes Americans Dying From Coronavirus Will "Take Down Trump's Presidency" https://t.co/XUBaj6Y8x1 Think. The fake news media wants you to die so that it hurts Pres. Trump. This is equivalent to Goebbels Nazi Propaganda". Twitter, March 12.

https://twitter.com/harveystaub1/status/1237926081480491008

Stieglitz, Stefan; Mirbabaie, Milad; Ross, Bjorn; Neuberger, Christoph (2018). "Social media analytics - Challenges in topic discovery, data collection, and data preparation". International journal of information management, n. 39, pp. 156-168.

https://doi.org/10.1016/j.ijinfomgt.2017.12.002

Syed-Abdul, Shabbir; Fernández-Luque, Luis; Jian, Wen-Shan; Li, Yu-Chuan; Crain, Steven; Hsu, Min-Huei; Wang, YaoChin; Khandregzen, Dorjsuren; Chuluunbaatar, Enkhzaya; Nguyen, Phung-Aanh; Liou, Der-Ming (2013). "Misleading health-related information promoted through video-based social media: Anorexia on YouTube". Journal of medical internet research, v. 15, n. 2, e30.

https://doi.org/10.2196/jmir.2237

Tatchell, Peter (2020). Peter Tatchell on Twitter: "Heroic \#HongKong bookseller \#GuiMinhai abducted from Thailand in 2015 by Beijing agents. Now jailed for 10 years on fake espionage charges. China announced sentence during coronavirus outbreak to bury it https://t.co/dJktPpkVQN FOLLOW @demosisto @CHRDnet @hrichina @joshuawongcf". Twitter, February 27.

https://twitter.com/PeterTatchell/status/1233113354253803521

Tolson, Andrew (2010). "A new authenticity? Communicative practices on YouTube". Critical discourse studies, v. 7, n. 4, pp. 277-289.

https://doi.org/10.1080/17405904.2010.511834

Trump, Donald (2020). Donald J. Trump on Twitter: «Vanity Fair Magazine, which will soon be out of business, and their third rate Fake reporters, who make up sources which don't exist, wrote yet another phony \&amp; boring hit piece. The facts are just the opposite. Our team is doing a great job with CoronaVirus!». Twitter, March 11.

https://twitter.com/realdonaldtrump/status/1237745593876873217

Túñez-López, José-Miguel; Toural-Bran, Carlos; Cacheiro-Requeijo, Santiago (2018). “Uso de bots y algoritmos para automatizar la redacción de noticias: Percepción y actitudes de los periodistas en España". El profesional de la información, v. 27, n. 4 , pp. $750-758$.

https://doi.org/10.3145/epi.2018.jul.04

Vázquez-Herrero, Jorge; Vizoso, Ángel; López-García, Xosé (2019). “Innovación tecnológica y comunicativa para combatir la desinformación: 135 experiencias para un cambio de rumbo". El profesional de la información, v. 28, n. 3, e280301. https://doi.org/10.3145/epi.2019.may.01 
Verweij, Peter (2012). "Twitter links between politicians and journalists". Journalism practice, v. 6, n. 5-6, pp. 680-691. https://doi.org/10.1080/17512786.2012.667272

Vosoughi, Soroush; Mohsenvand, Mostafa-Neo; Roy, Deb (2017). "Rumor gauge: Predicting the veracity of rumors on Twitter". ACM Transactions on knowledge discovery from data, v. 11, n. 4, article 50.

https://doi.org/10.1145/3070644

Wang, Tao; Brede, Markus; lanni, Antonella; Mentzakis, Emmanouil (2017). “Detecting and characterizing eating-disorder communities on social media". In: Proceedings of the Tenth ACM International conference on web search and data mining, pp. 91-100.

https://doi.org/10.1145/3018661.3018706

Wasserman, Stanley; Faust, Katherine (1994). Social network analysis: Methods and applications (vol. 8). Cambridge University Press. ISBN: 9781139788618

Wheeler, Dylan (2020). Educating Liberals on Twitter: "The stock market dropped 1200 points today - the single worst drop in its history. This is what happens when the Fake news Media scares the public into believing the Coronavirus is worse than the Spanish flu. They will do anything to hurt Trump's image before election season". Twitter, February 27. https://twitter.com/education4libs/status/1233146925689516032

White, Sean (2020). Sean White USMCSDI on Twitter: "Dear America: The ONLY difference between THIS pandemic of Coronavirus and the other hundreds we've dealt with is that FAKE NEWS has decided to POLITICIZE it because sCumbag, left wing slobs know NO shame NOBODY lost their minds like this when 13K Americans died of H1N1 in 2010". Twitter, March 12.

https://twitter.com/usmcsdi/status/1237895813667282945

Williams, Shirley A.; Terras, Melissa M.; Warwick, Claire (2013). "What do people study when they study Twitter? Classifying Twitter related academic papers". Journal of documentation, v. 69, n. 3, pp. 384-410.

https://doi.org/10.1108/JD-03-2012-0027

Wood, Michael J. (2018). "Propagating and debunking conspiracy theories on Twitter during the 2015-2016 Zika virus outbreak". Cyberpsychology, behavior, and social networking, v. 21, n. 8, pp. 485-490.

https://doi.org/10.1089/cyber.2017.0669

Wu, Shaomei; Hofman, Jake M.; Mason, Winter A.; Watts, Duncan J. (2011). "Who says what to whom on Twitter". Proceedings of the $20^{\text {th }}$ International Conference on world wide web - WWW'11, pp. 705-714.

https://doi.org/10.1145/1963405.1963504

Wukich, Clayton; Steinberg, Alan (2013). "Nonprofit and public sector participation in self-organizing information networks: Twitter hashtag and trending topic use during disasters: Self-organizing information networks". Risk, hazards \& crisis in public policy, v. 4, n. 2, pp. 83-109.

https://doi.org/10.1002/rhc3.12036

Xiong, Ying; Cho, Moonhee; Boatwright, Brandon (2019). "Hashtag activism and message frames among social movement organizations: Semantic network analysis and thematic analysis of Twitter during the \#MeToo movement". Public relations review, v. 45, n. 1, pp. 10-23.

https://doi.org/10.1016/j.pubrev.2018.10.014

Xu, Zhan (2019). "Personal stories matter: Topic evolution and popularity among pro- and anti-vaccine online articles". Journal of computational social science, v. 2, n. 2, pp. 207-220.

https://doi.org/10.1007/s42001-019-00044-w

Xu, Zhan; Ellis, Lauren; Umphrey, Laura R. (2019). "The easier the better? Comparing the readability and engagement of online pro- and anti-vaccination articles". Health education \& behavior, v. 46, n. 5, pp. 790-797.

https://doi.org/10.1177/1090198119853614

Yang, Haodong; Yang, Christopher C. (2013). "Harnessing social media for drug-drug interactions detection". 2013 IEEE International conference on healthcare informatics, pp. 22-29.

https://doi.org/10.1109/ICHI.2013.10

Yom-Tov, Elad; Fernández-Luque, Luis; Weber, Ingmar; Crain, Steven P. (2012). "Pro-anorexia and pro-recovery photo sharing: A tale of two warring tribes". Journal of medical internet research, v. 14, n. 6, e151.

https://doi.org/10.2196/jmir.2239

Zubiaga, Arkaitz; Liakata, Maria; Procter, Rob; Wong-Sak-Hoi, Geraldine; Tolmie, Peter (2016). “Analysing how people orient to and spread rumours in social media by looking at conversational threads". PLoS one, v. 11, n. 3, e0150989.

https://doi.org/10.1371/journal.pone.0150989 